\title{
Combination of metformin and p38 MAPK inhibitor, SB203580, reduced myocardial ischemia/reperfusion injury in non-obese type 2 diabetic Goto-Kakizaki rats
}

\author{
JANTIRA SANIT ${ }^{1,2}$, EAKKAPOTE PROMPUNT ${ }^{1,3}$, PUNYANUCH ADULYARITTHIKUL $^{1,2}$, \\ NUTTIKARN NOKKAEW ${ }^{1,2}$, PODSAWEE MONGKOLPATHUMRAT ${ }^{1,2}$, KANTAPICH KONGPOL $^{1,2}$, \\ ANUSAK KIJTAWORNRAT ${ }^{4}$, SOONTAREE PETCHDEE ${ }^{5}$, \\ STEPHANIE BARRÈRE-LEMAIRE $^{6}$ and SARAWUT KUMPHUNE ${ }^{1,2,7}$
}

\begin{abstract}
${ }^{1}$ Biomedical Research Unit in Cardiovascular Sciences (BRUCS); ${ }^{2}$ Graduate Program in Biomedical Sciences, Faculty of Allied Health Sciences, Naresuan University, Phitsanulok 65000; ${ }^{3}$ Department of Medical Technology, Faculty of Allied Health Sciences, University of Phayao, Phayao 56000; ${ }^{4}$ Department of Physiology, Faculty of Veterinary Science, Chulalongkorn University, Bangkok 10240; ${ }^{5}$ Department of Large Animal and Wildlife Clinical Science, Faculty of Veterinary Medicine, Kasetsart University, Nakhorn Pathom 73140, Thailand; ${ }^{6}$ IGF, CNRS, INSERM, University of Montpellier, 34094 Montpellier, France; ${ }^{7}$ Department of Medical Technology, Faculty of Allied Health Sciences, Naresuan University, Phitsanulok 65000, Thailand
\end{abstract}

Received March 2, 2018; Accepted June 25, 2019

DOI: 10.3892/etm.2019.7763

\begin{abstract}
Diabetic cardiomyopathy, especially myocardial ischemia reperfusion (I/R) injury, is a major cause of morbidity and mortality in type 2 diabetic patients. The increasing of basal p38 MAP Kinase (p38 MAPK) activation is a major factor that aggravates cardiac death on diabetic cardiomyopathy. In addition, metformin also shows cardio-protective effects on myocardial ischemia/reperfusion injury. In this study, we investigated the effect of the combination between metformin and p38 MAPK inhibitor (SB203580) in diabetic rats subjected to I/R injury. H9c2 cells were induced into a hyperglycemic condition and treated with metformin, SB203580 or the combination of metformin and SB203580. In addition, cells in both the presence and absence of drug treatment were subjected to simulated ischemia/reperfusion injury. Cell viability and cellular reactive oxygen species (ROS) were determined. Moreover, the Goto-Kakizaki (GK) rats were treated with metformin, SB203580, and the combination of metformin and SB203580 for 4 weeks. Diabetic parameters and cardiac functions were assessed. Finally, rat hearts were induced ischemia/reperfusion injury for the purpose of
\end{abstract}

Correspondence to: Professor Sarawut Kumphune, Biomedical Research Unit in Cardiovascular Sciences (BRUCS), Naresuan University, 99 Moo 9, Ta Pho, Muang, Phitsanulok 65000, Thailand E-mail: sarawutk@nu.ac.th

Key words: type II diabetes, cardioprotection, ischemia/reperfusion injury, non-obese, Goto-Kakizaki rat, metformin, p38 MAPK inhibitor, SB203580 infarct size analysis and determination of signal transduction. A high-glucose condition did not reduce cell viability but significantly increased ROS production and significantly decreased cell viability after induced sI/R. Treatment using drugs was shown to reduce ROS generation and cardiac cell death. The GK rats displayed diabetic phenotype by increasing diabetic parameters and these parameters were significantly decreased when treated with drugs. Treatment with metformin or SB203580 could significantly reduce the infarct size. Interestingly, the combination of metformin and SB203580 could enhance cardio-protective ability. Myocardial I/R injury significantly increased p38 MAPK phosphorylation, Bax/Bcl-2 ratio and caspase-3 level. Treatment with drugs significantly decreased the p38 MAPK phosphorylation, Bax/Bcl-2 ratio, caspase-3 level and increased Akt phosphorylation. In conclusion, using the combination of metformin and SB203580 shows positive cardio-protective effects on diabetic ischemic cardiomyopathy.

\section{Introduction}

Diabetes is a non-communicable disease, is a major cause of morbidity and mortality in worldwide. Particularly, the International Diabetes Federation (IDF) has reported that cases of type 2 diabetes will increase to 693 million by 2045 (1). Type 2 diabetes is a chronic metabolic disorder caused by abnormal insulin signaling. The major characteristic of diabetes is insulin resistance, or hyperglycemia, where blood glucose levels are elevated $(2,3)$. In addition, the progression of type 2 diabetes leads to the microvascular and macrovascular complications (4) especially, cardiovascular diseases (CVD). Myocardial ischemia/reperfusion (I/R) injury is one of these such cardiovascular diseases mostly found in type 2 diabetic 
patients (5) and causes $52 \%$ of the deaths in type 2 diabetic patients (with the cause of death attributable to their condition) (6). Moreover, it has been reported that type 2 diabetes with myocardial I/R injury has an aggravated pathophysiology in the heart, including an increase in reactive oxygen species (ROS), increase in the size of myocardial infarction (7) (which relates to an increase in cardiac death rates), left ventricular hypertrophy and contractile dysfunction (8) and cardiac dysfunction (9).

The major factor of cardiac impairment in diabetic cardiomyopathy is an increasing level of basal p38 mitogen-activated protein kinases (p38 MAPK) activation. p38 MAPK is a serine/threonine protein kinase, which responds to several cellular processes and external stress signaling, such as cell differentiation, cell proliferation, inflammation and cells death $(10,11)$. It has been reported that the increasing rates of p38 MAPK activation is also induced by myocardial $\mathrm{I} / \mathrm{R}$ injury condition and diabetic disease, which results in myocardial pathology, including elevated pro-inflammatory cytokines release, induced oxidative stress, induced cardiac dysfunction (12,13), cardiac apoptosis and an increased size of myocardial infarct (14). The inhibition of p38 MAPK activation by 38 MAPK inhibitor is an effective method. The SB203580 is a well-studied selective inhibitor used in complete block p38 MAPK activation. Moreover, previous study has demonstrated that SB203580 could improve cardiac function, inhibit infarct area expansion, reduce scar tissue and suppress myocardial fibrosis in animal models of myocardial ischemia/reperfusion condition (15).

The combination of controlling blood glucose levels and improving insulin sensitivity is the most effective treatment for diabetic patients. Metformin is one of the anti-diabetic drugs that belongs to the biguanide drug family and is widely used in diabetic treatment around the world. Metformin is not only used to control blood glucose levels, but also shows cardio-protective effects, including improving heart failure progression in animal models (16), preventing left ventricular dysfunction, improving cardiac function and survival in murine models of heart failure (17) and inhibiting reactive oxygen species (ROS) production, reducing inflammatory and apoptosis in $\mathrm{H} 9 \mathrm{c} 2$ cardiomyocytes-induced high-glucose and hypoxia/reoxygenation injury (18).

According to the above information, it is indicated that the aggravation of cardiac death in diabetic cardiomyopathy, especially diabetes complicated with myocardial ischemia/reperfusion disease, may be due to a failure to control blood glucose levels together with an increase of p38 MAPK activation. Although, treatment with metformin itself or p38 MAPK inhibitor itself could decrease cardiac death rates in patients with type 2 diabetes or myocardial ischemia/reperfusion. However, this alone is insufficient to prevent the cardiac death in patients with diabetes complicated with myocardial ischemia/reperfusion injury disease. Therefore, treatment with the combination of metformin and p38 MAPK inhibitor (SB203580) could have a therapeutic potential for patients with diabetes with myocardial ischemia/reperfusion injury disease. However, the effects of this combination of metformin and SB203580 on patients with diabetes complicated with myocardial ischemia/reperfusion injury have not been intensively investigated. So, the objective of this study was to determine the effect of metformin combined with SB203580 in terms of how diabetic parameters can be controlled and cardiac death rates in cardiac cell line (H9c2 cell) and type 2 diabetic models (GK rats) subjected to myocardial ischemia/reperfusion injury condition.

\section{Materials and methods}

Chemicals and reagents. Dulbecco's modified Eagle's medium (DMEM), fetal bovine serum and trypsin-EDTA were purchased from Gibco BRL; Life Technologies Inc. Other purchases included 2',7'-Dichlorofluorescin Diacetate from Merck, 3-(4,5-dimethyl-2-thiazol)-2,5-diphenyl-2Htetrazolium bromide (MTT) from Ameresco, metformin from MERCK Serono, p38 MAPK inhibitor (SB203580) from Tocris Bioscience. Other chemicals were purchased from Sigma Chemical Company.

Cell culture. The rat cardiac myoblast cell line $(\mathrm{H} 9 \mathrm{c} 2$ cell line) was purchased from the American Type Cell Collection (ATCC; no. CRL-1446). The cell was maintained in Dulbecco's modified Eagle's medium (DMEM) $\left(\mathrm{Gibco}^{\circledR}\right)$ supplemented with $5,000 \mathrm{U} / \mathrm{ml}$ of penicillin, $5,000 \mu \mathrm{g} / \mathrm{ml}$ of streptomycin $\left(\right.$ Gibco $\left.^{\circledR}\right)$ and $10 \%$ fetal bovine serum (FBS) $\left(\right.$ Gibco $\left.^{\circledR}\right)$. Cells were cultured at $37^{\circ} \mathrm{C}, 5 \% \mathrm{CO}_{2}$ and $95 \% \mathrm{O}_{2}$ throughout the experiment. When the cell density was more than $70-80 \%$ confluent, the cell was sub-cultured with trypsin.

An in vitro simulated ischemia/reperfusion (sI/R) condition. For an in vitro simulated ischemia, the culture media was removed and replaced with 'ischemic buffer', which is modified Krebs-Henseleit buffer (137 mM NaCl, $3.8 \mathrm{mM}$ $\mathrm{KCl}, 0.49 \mathrm{mM} \mathrm{MgCl}_{2}, 0.9 \mathrm{mM} \mathrm{CaCl}_{2}$, and $4.0 \mathrm{mM}$ HEPES) supplemented with $20 \mathrm{mM}$ 2-deoxyglucose, $20 \mathrm{mM}$ sodium lactate, and $1 \mathrm{mM}$ sodium dithionite at $\mathrm{pH}$ 6.5. The control buffer comprises Krebs-Henseleit buffer supplemented with $20 \mathrm{mM}$ D-glucose and 1mM sodium pyruvate. Then, the cells were incubated at $37^{\circ} \mathrm{C}, 5 \% \mathrm{CO}_{2}$ for $40 \mathrm{~min}$ before changing to complete medium for reperfusion at $37^{\circ} \mathrm{C}, 5 \% \mathrm{CO}_{2}$ for $24 \mathrm{~h}$

Determination of cell viability by MTT assay. For cell viability measurement, MTT assay was used based on mitochondria dehydrogenases activity. The H9c2 cells were seeded at a density of $5 \times 10^{3}$ cells/well in a 96 -well plate until $80 \%$ confluence was reached. After treatments or at the end of study protocols, the culture medium was discarded and replaced with $0.5 \mathrm{mg} / \mathrm{ml} \mathrm{MTT} \mathrm{reagent} \mathrm{and} \mathrm{incubate} \mathrm{at} 37^{\circ} \mathrm{C}$ for $2 \mathrm{~h}$. After incubation, the excess MTT reagent was removed and the formazan dye was solubilized by adding $100 \mu \mathrm{l}$ of dimethysulfoxide (DMSO). The optical density (OD) was measured using a spectrophotometric method at $\lambda 490 \mathrm{~nm}$ using DMSO as a blank. The relative percentage of cell viability was compared against the control group.

Determination of intracellular reactive oxygen species (ROS) production. Reactive oxygen species detection was performed by 2'7-dichlorofluorescein diacetate (DCFH-DA) dye. $\mathrm{H} 9 \mathrm{c} 2$ cells were cultured in a 96-well plate at the density of $5 \times 10^{3} \mathrm{cell} /$ well at $37^{\circ} \mathrm{C}, 5 \% \mathrm{CO}_{2}$, and $95 \% \mathrm{O}_{2}$ until $80 \%$ confluence was reached. The medium was discarded and cells were 
washed with PBS solution before being incubated with culture medium or condition medium containing $25 \mu \mathrm{M}$ DCFH-DA for $24 \mathrm{~h}$ at $37^{\circ} \mathrm{C}$. The intracellular production of ROS was determined by measuring the fluorescence intensity with an EnSpire Multimode Plate Readers (PerkinElmer). The filter suitable for detecting the signal gave an excitation wavelength of $\lambda 498 \mathrm{~nm}$ and emission wavelength of $\lambda 522 \mathrm{~nm}$.

Experimental animals. Male type 2 diabetic Goto-Kakizaki $(\mathrm{GK})$ rats $(\mathrm{n}=40)$ and age-matched Wistar rats $(\mathrm{n}=10)$ weighing approximately 200-250 g were purchased from Nomura Siam International. All animals were maintained under environmentally controlled conditions $\left(22 \pm 1^{\circ} \mathrm{C}, 12 \mathrm{~h}\right.$ light: Dark cycle) at the Center for Animal Research, Naresuan University, Phitsanulok, Thailand. All protocols used in this study were approved by the committee of the Center for Animal Research, Naresuan University (approval no. NU-AE581023).

Study groups and treatment. All rats were maintained for 4 weeks after being purchased and the glycemic parameters, including fasting blood glucose, hemoglobin $\mathrm{A}_{1 \mathrm{c}}$ levels, and oral glucose tolerance testing (OGTT), were performed for the purposes of confirming the diabetic model. Then, the rats were divided into 2 major groups, including (1) the control group (Wistat rats; $\mathrm{n}=10$ ) and (2) the diabetic group (GK rats; $\mathrm{n}=40$ ). Diabetic GK rats were sub-divided into 4 subgroups, including: i) diabetic group ( $\mathrm{GK}$ rats; $\mathrm{n}=10)$ which received $1.5 \mathrm{ml}$ of deionized water twice daily (b.i.d) by oral gavage and $0.2 \mathrm{ml}$ of deionized water every 3 days by intraperitoneal (IP) injection as a control treatment group; ii) diabetic group treated with metformin $(n=10)$ which received metformin $15 \mathrm{mg} / \mathrm{kg}$.BW twice daily (b.i.d) by oral gavage; iii) diabetic group treated with SB203580 $(n=10)$ which received $2 \mathrm{mg} / \mathrm{kg}$.BW of SB203580 with a volume of $0.2 \mathrm{ml}$ by intraperitoneal (IP) injection every 3 days; and iv) diabetic group treated with metformin and SB203580 or so called 'combination group' $(\mathrm{n}=10)$ which received metformin $15 \mathrm{mg} / \mathrm{kg} . \mathrm{BW}$ b.i.d by oral gavage and $2 \mathrm{mg} / \mathrm{kg}$. BW of SB203580 IP. A rat having weight loss $>20 \%$, and lack of social behavior, was exclude from the study.

Determination of fasting blood glucose (FBS). The rats were fasted for a period of 12-14 h, and then blood from the rats tail veins was collected for the measurement of blood glucose levels by glucometer (SD GlucoNavii ${ }^{\circledR}$ GDH; SB Biosensor). The rats' tails were cleaned with $70 \%$ alcohol and the blood was drawn using a $1 \mathrm{ml}$ needle, then dropped onto a glucose strip and measured by a glucometer. The amount of electricity is proportional to the glucose content in the sample. The quality control for blood glucose was performed using the quality control material provided by SD Biosensor.

Determination of oral glucose tolerance test (OGTT). All of the rats were fasted for a period of 12-14 h, and then the blood was collected from rats' tail veins as a baseline. Then, the rats were fed with $40 \%$ (w/v) glucose solution by oral gavage at an amount equal to $2 \mathrm{~g} / \mathrm{kg}$ body weight. The blood was collected from tail veins at 30, 60, 90 and $120 \mathrm{~min}$ after the glucose treatment and then analyzed for blood glucose with a glucometer.
Determination of hemoglobin $A_{l c}\left(H b A_{l c}\right)$. The $\mathrm{HbA}_{1 \mathrm{c}}$ test was performed by using CLOVER $\mathrm{A}_{1 \mathrm{c}}{ }^{\mathrm{TM}}$ Self-analyzer. The blood samples from the rats' tail veins were collected and dropped onto a test cartridge and measured by CLOVER $\mathrm{A}_{1 \mathrm{c}}{ }^{\mathrm{TM}}$ Self system. Finally, the percentages of Hemoglobin $\mathrm{A}_{1 \mathrm{c}}\left(\mathrm{HbA}_{1 \mathrm{c}} \%\right)$ of the blood samples were represented on an LCD screen of CLOVER $\mathrm{A}_{1 \mathrm{c}}{ }^{\mathrm{TM}}$ Self machine. The quality control for $\mathrm{HbA}_{\mathrm{lc}}$ was performed using the quality control material provided by EuriMedix Company.

Determination of plasma insulin level. The plasma insulin levels were determined by Sandwich ELISA (Millipore). The plasma samples were added to a microtiter plate coated with monoclonal mouse anti-rat insulin antibodies. After that, unbound material from the samples was washed away and the immobilized biotinylated antibodies were added. The microtiter plate had the substrate 3,3',5,5'-tetramethybenzidine added. The enzyme activity was measured by a spectrophotometer (BioTek) with an absorbance at $450 \mathrm{~nm}$, with a corrected wavelength at $590 \mathrm{~nm}$. The plasma insulin concentration in the unknown samples was derived by interpolation from a reference curve generated in the same assay with reference standard of known concentration of rat insulin.

Determination of cardiac function by echocardiography. The echocardiography was performed by a veterinary cardiologist before and after drug treatment for 4 weeks. In brief, rats were intraperitoneal injected (IP) with a Ketamine/xylazine cocktail (91 mg/kg Ketamine; $9.1 \mathrm{mg} / \mathrm{kg}$ Xylazine) at a concentration of $0.1 \mathrm{ml} / 100 \mathrm{~g}(\mathrm{v} / \mathrm{w})$ as an anesthetic. Then, the chest hair was removed, and echocardiography was performed using Mindray M9 (Mindray Medical Co., Ltd.) equipped with 4-10 MHz phased array cardiac probes (Mindray Medical Co., Ltd.) for measuring cardiac function. The cardiac function parameters were analyzed, which included Ejection fraction (EF), End-Diastolic volume (EDV), End-Systolic volume (ESV), Interventricular septum thickness at end-diastole (IVSd), Interventricular septum thickness at end-systole (IVSs), Left ventricular internal dimension at end-diastole (LVIDd), Left ventricular internal dimension at end-systole (LVIDs), Left ventricular posterior wall thickness at end-diastole (LVPWd), Left ventricular posterior wall thickness at end-systole (LVPWs), Cardiac output (CO), Stock volume (SV) and Heart rate (HR).

An ex vivo myocardial ischemia/reperfusion injury by Langendorff perfusion. The ex vivo ischemia/reperfusion protocol was derived from protocols of the previous study (14). Rats ( $n=6)$ were anesthetized with IP injection of pentobarbital $(100 \mathrm{mg} / \mathrm{kg})$ and heparin $(150 \mathrm{U})$, which was used as a terminal procedure prior to harvesting vital organs such as the heart. The deep anesthesia was closely observed and confirmed by a lack of both toe pinch and corneal reflexes. After that, the hearts were rapidly isolated and placed in ice-cold modified Krebs-Henseleit buffer (KHB; $118.5 \mathrm{mM}$ of $\mathrm{NaCl}, 25.0 \mathrm{mM}$ of $\mathrm{NaHCO}_{3}, 4.75 \mathrm{mM}$ of KCl, $1.18 \mathrm{mmol}$ of $\mathrm{KH}_{2} \mathrm{PO}_{4}, 1.19 \mathrm{mM}$ of $\mathrm{MgSO}_{4}, 11.0 \mathrm{mM}$ of D-glucose, and $1.4 \mathrm{mM}$ of $\left.\mathrm{CaCl}_{2}\right)$. The excised heart was cannulated via the aorta and retrogradely perfused on a Langendorff system at a constant pressure of $80 \mathrm{mmHg}$ with $\mathrm{KHB}$ equilibrated with $95 \% \mathrm{O}_{2}$ and $5 \% \mathrm{CO}_{2}$ at $37^{\circ} \mathrm{C}$. The hearts were perfused with $\mathrm{KHB}$ for $30 \mathrm{~min}$ (as 
a stabilization period). Then, the hearts were subjected to global ischemia by halting perfusion for a duration of $30 \mathrm{~min}$ (no-flow). Reperfusion was obtained with the perfusion of $\mathrm{KHB}$ for a further $2 \mathrm{~h}$. At the end of the protocol, the hearts were perfused for $1 \mathrm{~min}$ with $5 \mathrm{ml}$ of $1 \%$ triphenyltetrazolium chloride (TTC) in phosphate-buffered saline (PBS) and then incubated in an identical solution at $37^{\circ} \mathrm{C}$ for $10 \mathrm{~min}$. The atria were then removed and the hearts were blotted dry, weighed, and stored at $20^{\circ} \mathrm{C}$ for up to 1 week. Hearts were then thawed, placed in $2.5 \%$ glutaraldehyde for $1 \mathrm{~min}$, and set in $5 \%$ agarose. The agarose heart blocks were sectioned from apex to base in $1 \mathrm{~mm}$ slices using a Vibratome (Agar Scientific). After sectioning, slices were placed overnight in $10 \%(\mathrm{v} / \mathrm{v})$ formaldehyde at room temperature before being transferred to a phosphate-buffered saline solution for an additional 1 day at $4^{\circ} \mathrm{C}$. Sections were then compressed between glass plates (1 mm apart) and scanned. All analyses of infarct size were performed by two investigators who were blind with regard to the information regarding the group assignments.

Determination of signal transduction in organ level by western blot analysis. The rats $(\mathrm{n}=6)$ were anesthetized and hearts were cannulated. After that, the cannulated hearts were perfused with the K-H buffer for $40 \mathrm{~min}$ and then the flow of K-H buffer was halted for $10 \mathrm{~min}$. After $10 \mathrm{~min}$, the hearts were rapidly snapped frozen. $500 \mu 1$ of homogenization buffer was added to the heart samples for homogenization. The heart samples that were homogenated were centrifuged at $15,366 \times \mathrm{g}, 4^{\circ} \mathrm{C}$ for $10 \mathrm{~min}$. Then, the samples were collected and added in equal volume of $2 \mathrm{X}$ SDS-PAGE sample buffers; containing $10 \%(\mathrm{v} / \mathrm{v}) 2$-mercaptoethanol and bromophenol blue dye. The sample was boiled for $10 \mathrm{~min}$. The heart proteins were separated in SDS-PAGE gels at the final amount of protein at $100 \mu \mathrm{g}$ per lane. Electrophoresis was performed at $120 \mathrm{~V}$ for $2 \mathrm{~h}$. After separation, proteins were transferred to Polyvinylidene fluoride (PVDF) membranes (Hybond-P; GE Healthcare Life Sciences) using a semi-dry apparatus under an electrical current of $12 \mathrm{mV}$, for $45 \mathrm{~min}$. Following transfer, membranes were incubated in a blocking solution (5\% (w/v) of dried skimmed milk powder, in TBST) for $1 \mathrm{~h}$ with gentle shaking at room temperature. The membranes, which transferred protein, were incubated with primary antibodies for phosphorylated-Akt (Santa Cruz Biotechnology, Inc., \#sc-7985), total-Akt (Santa Cruz Biotechnology, Inc., \#sc-8312), phosphorylated p38 (Santa Cruz Biotechnology, Inc., \#sc-17852), total-p38 (Santa Cruz Biotechnology, Inc., \#sc-535), Bax (Santa Cruz Biotechnology, Inc., \#sc-493), Bcl-2 (Santa Cruz Biotechnology, Inc., \#sc-492) caspase 3 (Santa Cruz Biotechnology, Inc., \#sc-7148) and GAPDH (Merck, \#ABS16) (All of primary antibodies were diluted at 1:1,000 in $1 \%(\mathrm{w} / \mathrm{v})$ skimmed milk + TBST buffer) and the horseradish peroxidase-conjugated secondary antibody (goat anti-rabbit (Merck, \#AP132P) and rabbit anti-goat (Merck, \#AP106P), which was diluted at 1:5,000 in $1 \%(\mathrm{w} / \mathrm{v})$ skimmed milk + TBST, after the heart protein was separated in SDS-PAGE. The band intensity quantitation was determined by Image LabTM 2.0 Software (Bio-Rad Laboratories, Inc.).

Statistical analysis. All values are expressed as the mean \pm SEM. All comparisons involving the two groups were determined in terms of significance using Student's t-test and more than one group was assessed in terms of significance using a one-way ANOVA, followed (when appropriate) by the Tukey-Kramer test. $\mathrm{P}<0.05$ was considered to indicate a statistically significant difference.

\section{Results}

An in vitro hyperglycemia enhances the sensitivity to cellular injury in H9c2 subjected simulated ischemia/reperfusion via increase intracellular ROS production. The H9c2 cells were cultured until the confluency of $80 \%$ was reached, and then incubated in a high-glucose condition for $24 \mathrm{~h}$, which was a complete medium supplemented with D-glucose solution to a final concentration of glucose in culture medium at $33 \mathrm{mM}$. The result showed that the in vitro hyperglycemic condition did not reduce cell viability of $\mathrm{H} 9 \mathrm{c} 2$ cells when compared to the control group $(100.00 \% \pm 0.00$ vs. $98.92 \% \pm 1.84)$ (Fig. 1A). However, exposure to high glucose could significantly increase intracellular ROS production when compared to the normal culture condition (2,305 A.U. \pm 61.26 vs. 2,832 A.U. \pm 51.96 ) (Fig. $1 \mathrm{~B} ; \mathrm{P}<0.05$ ). An in vitro simulated ischemia/reperfusion (sI/R) could significantly reduce cell viability when compared to the control condition $(100.0 \% \pm 0.00$ vs. $81.50 \% \pm 1.77$ ) (Fig. $1 \mathrm{~A} ; \mathrm{P}<0.05)$. Moreover, cells in hyperglycemic condition subjected to sI/R exhibited a significantly greater reduction in cell viability when compared to $\mathrm{H} 9 \mathrm{c} 2$ in normal culture condition $(81.50 \% \pm 1.77$ vs. 59.92\% \pm 5.50$)$ (Fig. 1A; $\mathrm{P}<0.05$ ).

Metformin reduces injury in H9c2 cell subjected to hyperglycemia and simulated ischemia/reperfusion by reducing intracellular ROS production. A hyperglycemic condition showed a slight increase in cell viability $(100.00 \% \pm 0.00$ vs. $105.5 \% \pm 2.60)$, which was significantly increased when treated with metformin in hyperglycemic condition $(100.00 \% \pm 0.00$ vs. $115.6 \% \pm 3.09)$ (Fig. $2 \mathrm{~A} ; \mathrm{P}<0.05)$. The result showed that cell viability of cells under a hyperglycemic condition that were subjected to sI/R was significantly reduced when compared to the control group $(100.00 \% \pm 0.00$ vs. 47.06\% \pm 2.34 ) (Fig. 2B; $\mathrm{P}<0.05$ ). Treatment with metformin could significantly decrease cell death (Fig. 2B). Metformin treatment could significantly reduce hyperglycemic-induced intracellular ROS production (2,832 A.U. \pm 51.96 vs. 2,598 A.U. \pm 36.18 ) (Fig. 2C; P<0.05).

p38 MAPK inhibitor, SB203580, reduces injury in $\mathrm{H} 9 \mathrm{c} 2$ cells subjected to hyperglycemia and simulated ischemia/reperfusion. The results from cell viability showed that a hyperglycemic condition caused a slight increase in cell viability $(100.00 \% \pm 0.00$ vs. $107.9 \% \pm 1.67)$, and treatment with SB203580 did not affect cell viability $(110.4 \% \pm 2.54)$ (Fig. 3A). Cells exposed to the hyperglycemic condition and subjected to sI/R had significantly reduced cell viability when compared to the control group $(100.00 \% \pm 0.00$ vs. $41.39 \% \pm 2.80$ ) (Fig. 3B; $\mathrm{P}<0.05$ ). Treatment with SB203580 could significantly decrease cell death (Fig. 3B). In addition, SB203580 treatment could significantly reduce hyperglycemic induced intracellular ROS production (2,832 A.U. \pm 51.96 vs. 2,399 A.U.土54.27) (Fig. 3C). 
Combination of metformin and SB203580 reduces injury in H9c2 cell subjected to hyperglycemia and simulated ischemia/reperfusion. The combination of metformin and SB203580 showed no cytotoxicity to H9c2 cells since there were no significant differences in cell viability in each group compared to the control group $(100.00 \% \pm 0.00$ vs. $95.15 \% \pm 2.70)$ (Fig. 4A; P>0.05). In addition, combining metformin and SB203580 treatment could significantly decrease cell death in a hyperglycemic condition subjected to sI/R (Fig. 4B) and reduced intracellular ROS production when compared to the cells exposed to hyperglycemic condition (2,615 A.U. \pm 71.57 vs. 2,832 A.U. \pm 51.96 ) (Fig. 4C).

Confirmation of lean type 2 diabetic model of Goto-Kakizaki (GK) rats. To ensure that the lean type 2 diabetic animal model was valid for study, measurement of several glycemic parameters were performed. To confirm the non-obese or lean animal model, the rats were measured in terms of body weight and the growth rate at 7, 15 and 20 weeks of age. The growth curve was plotted using body weight (Fig. 5A) and the linear regression of the growth was analyzed. The slope of the graph represented the growth rate. The result showed that the linear equation of Wistar rats and GK rats was $y=22.95 x-1.758$ and $y=14.02 x-0.4524$, respectively. The slope of growth curve in Wistar rats was greater than GK rats. This could suggest the lean animal model.

The glycemic measurement showed that the mean FBG level of GK rats was significantly higher than that of Wistar rats $(143.6 \pm 3.58$ vs. $84.00 \pm 4.51 \mathrm{mg} / \mathrm{dl})$ (Fig. $5 \mathrm{~B}$; $\mathrm{P}<0.05)$. The mean percentage of $\mathrm{HbA}_{1 \mathrm{c}}$ level of $\mathrm{GK}$ rats was also higher than that of Wistar rats $(6.473 \pm 0.1$ vs. $4.120 \pm 0.04 \%, \mathrm{P}<0.05)$. The results from oral glucose tolerance test showed the impairment of glucose tolerance in GK rats. The mean FBG level $2 \mathrm{~h}$ after glucose intake in GK ratss was significantly higher than that in Wistar rats $(265.6 \pm 26.59$ vs. $111.7 \pm 6.499 \mathrm{mg} / \mathrm{dl}, \mathrm{P}<0.05)$. These results confirmed the diabetic-like model of GK rats.

Metformin and SB203580 improved glycemic parameters in lean T2DM rats. After 4 weeks of drugs treatment, blood was collected for measuring FBS and $\mathrm{HbA}_{1 \mathrm{c}}$ levels. The result showed that the FBG level of the diabetic group was significantly higher when compared to the control group $(153.6 \pm 7.27 \mathrm{mg} / \mathrm{dl}$ vs. $87.67 \pm 3.22 \mathrm{mg} / \mathrm{dl} ; \mathrm{P}<0.05)$. Treatment of metformin (113.3 \pm 2.99$)$, or SB203580 $(106.9 \pm 4.36)$, and the combination of metformin and SB203580 (113.2 \pm 3.79$)$ significantly reduced FBS levels when compared to the diabetic group (Fig. 6A; $\mathrm{P}<0.05$ ).

Similar results were observed in $\mathrm{HbA}_{1 \mathrm{c}}$ levels. The result showed that the percentage $\mathrm{HbA}_{1 \mathrm{c}}$ of the diabetic group was significantly higher than the control group $(6.70 \pm 0.108$ vs. $4.38 \pm 0.113 \% ; \mathrm{P}<0.05)$. Treatment with metformin significantly reduced the percentage of $\mathrm{HbA}_{1 \mathrm{c}}$ when compared to the diabetic group $(5.36 \pm 0.224$ vs. $6.70 \pm 0.108 \%$; $\mathrm{P}<0.05)$. However, treatment with SB203580 alone failed to showed any significant reduction in the $\mathrm{HbA}_{1 \mathrm{c}}$ level but not when compared to the diabetic group $(6.13 \pm 0.159$ vs. $6.70 \pm 0.108 \%)$ (Fig. 6B). A combination of metformin and SB203580 significantly reduced the percentage of $\mathrm{HbA}_{1 \mathrm{c}}$ when compared to the diabetic group ( $5.03 \pm 0.094$ vs. $6.70 \pm 0.108 \%$; $\mathrm{P}<0.05)$, but was unable to further reduce $\mathrm{HbA}_{\mathrm{lc}}$ when compared to metformin or the SB203580 treated group.
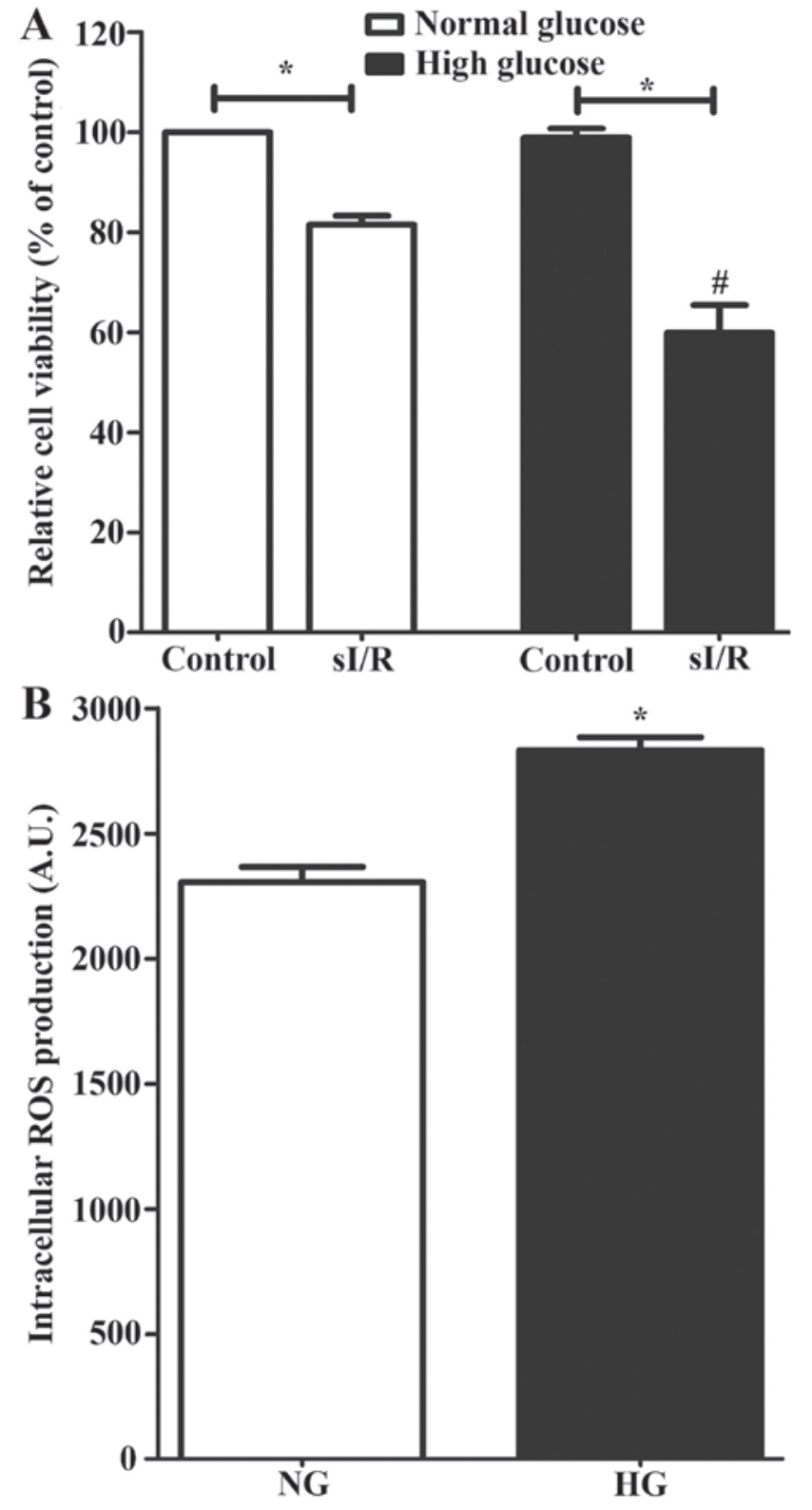

Figure 1. Effect of high-glucose condition and sI/R condition on H9c2 cells. (A) $\mathrm{H} 9 \mathrm{c} 2$ cells were induced with high-glucose condition using $33 \mathrm{mM}$ D-glucose solution for $24 \mathrm{~h}$ and the cell viability was determined. ${ }^{*} \mathrm{P}<0.05$; ${ }^{\#} \mathrm{P}<0.05$ vs. high-glucose control group by ANOVA. (B) H9c2 cells were incubated in high-glucose solution supplemented with 2'7-dichlorofluorescein diacetate dye for $24 \mathrm{~h}$ and the intracellular ROS production was measured. ${ }^{*} \mathrm{P}<0.05$ vs. NG. Each bar graph represents the mean \pm SEM. ROS, reactive oxygen species; sI/R, simulated ischemia/reperfusion; NG, normal glucose; $\mathrm{HG}$, high glucose.

The results showed that plasma insulin levels in all of diabetic groups were significantly lower than those of the control Wistar rats (Fig. 6C). Treatment with metformin and a combination of metformin and SB203580 were able to significantly reduce the plasma insulin levels when compare to the diabetic group $(3.210 \pm 1.338,4.770 \pm 1.184$ vs. $9.233 \pm 0.6731 \mathrm{ng} / \mathrm{ml} ; \mathrm{P}<0.05$, respectively). In contrast, the plasma insulin levels in the GK rats treated with SB203580 $(11.73 \pm 3.075 \mathrm{ng} / \mathrm{ml})$ were significantly higher compared to the metformin treated group and the drug combination group whereas there was no significant difference when compared to the diabetic group. 

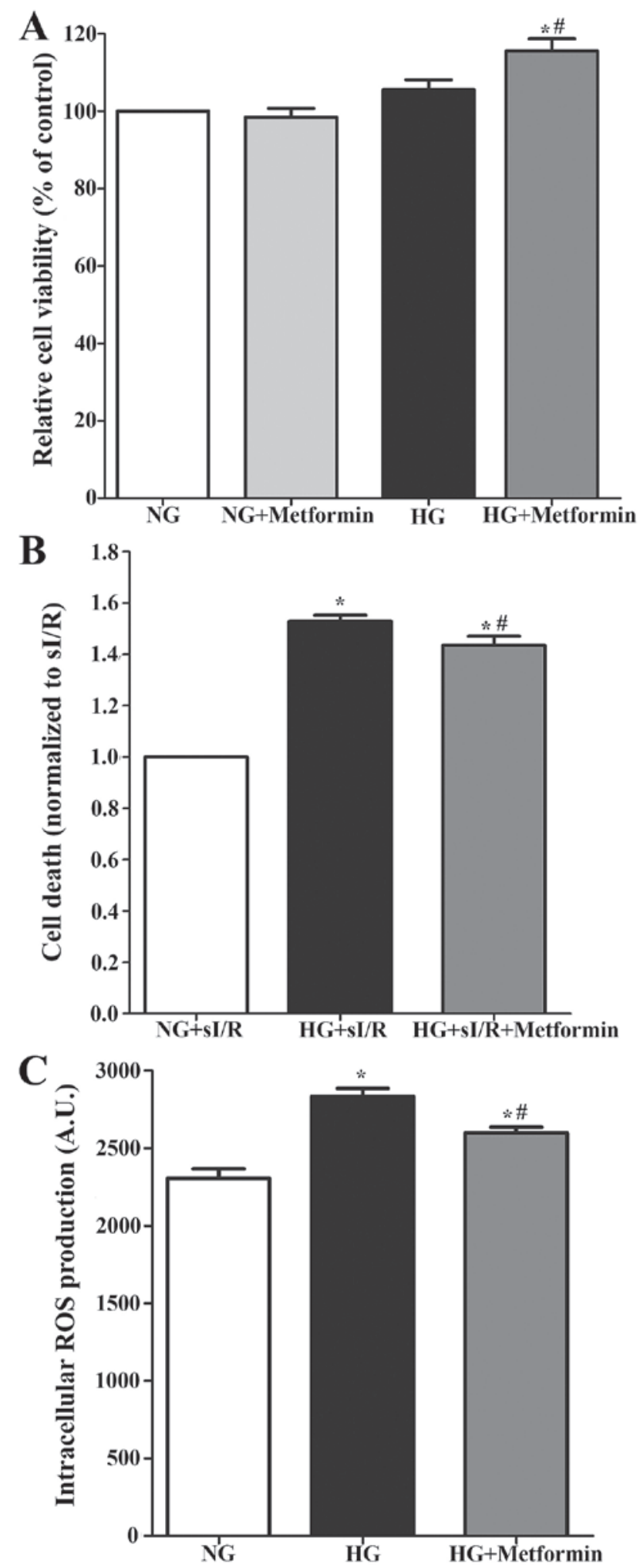

Figure 2. Determination of the effect of metformin treatment on H9c2 cells in high-glucose and sI/R condition. (A) H9c2 cells were induced with high-glucose condition supplemented with or without $3 \mathrm{mM}$ of metformin for $24 \mathrm{~h}$ and the cell viability was determined by an MTT cell survival assay. ${ }^{*} \mathrm{P}<0.05$ vs. NG; ${ }^{\#} \mathrm{P}<0.05$ vs. HG determined by ANOVA. (B) H9c2 cells in high-glucose condition treated with metformin for $24 \mathrm{~h}$ was simulated ischemia for $40 \mathrm{~min}$ followed by $24 \mathrm{~h}$ of reperfusion. ${ }^{*} \mathrm{P}<0.05 \mathrm{vs}$. NG+sI/R; ${ }^{\#} \mathrm{P}<0.05$ vs. $\mathrm{HG}+\mathrm{sI} / \mathrm{R}$ determined by ANOVA. (C) H9c2 cells were induced with a high-glucose condition and treated with metformin supplement with 2'7-dichlorofluorescein diacetate dye for $24 \mathrm{~h}$. Intracellular ROS production was measured. Each bar graph represents the mean $\pm \mathrm{SEM}$. ${ }^{*} \mathrm{P}<0.05$ vs. NG; ${ }^{\text {"P }} \mathrm{P} 0.05$ vs. HG determined by ANOVA. ROS, reactive oxygen species; NG, normal glucose; HG, high glucose; sI/R, simulated ischemia/reperfusion.
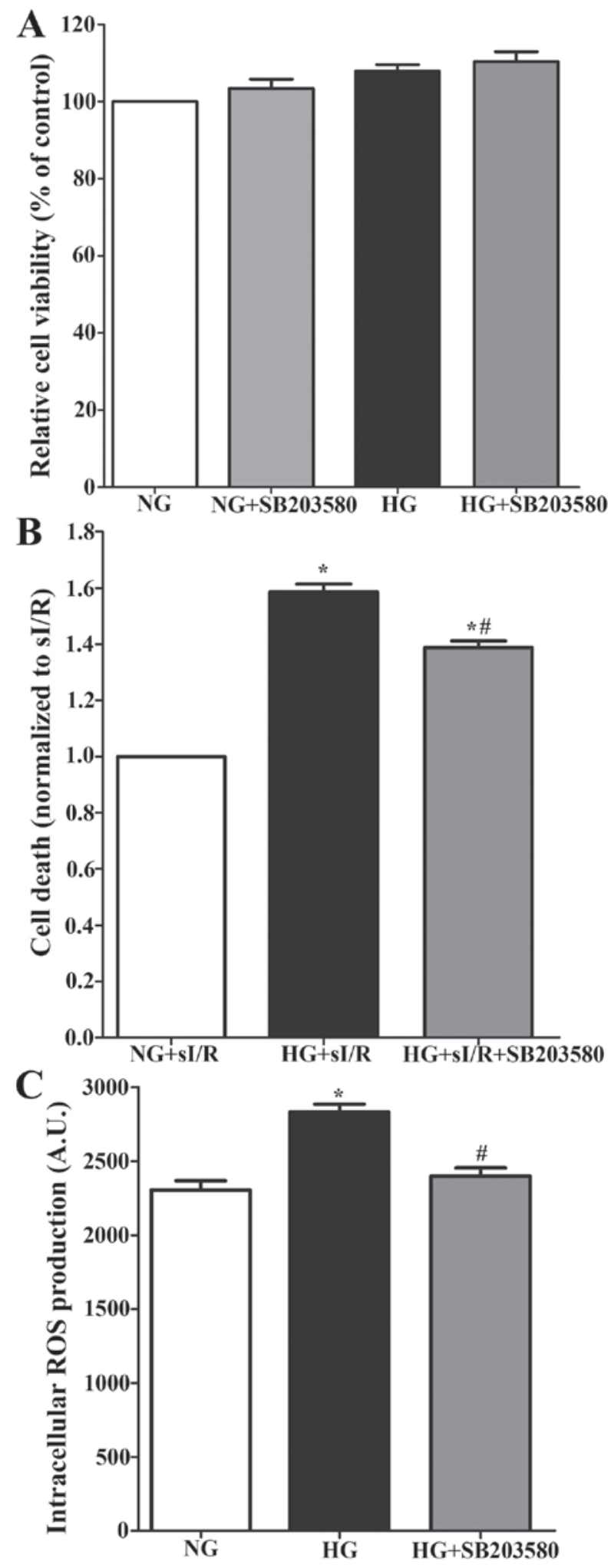

Figure 3. Determination of the effect of treatment with SB203580 in H9c2 cells in high-glucose and sI/R condition. The H9c2 cell, which induced high-glucose condition, was treated with or without $10 \mu \mathrm{M}$ p38 MAPK inhibitor (SB203580) for $24 \mathrm{~h}$. (A) Cell viability was measured by an MTT cell survival assay. The $\mathrm{H} 9 \mathrm{c} 2$ cell induced high-glucose was treated with SB203580 for $24 \mathrm{~h}$. (B) Then, the cell was simulated ischemia for $40 \mathrm{~min}$ followed by $24 \mathrm{~h}$ of reperfusion. ${ }^{\mathrm{P}}<0.05$ vs. $\mathrm{NG}+\mathrm{sI} / \mathrm{R}$; $\mathrm{P}<0.05 \mathrm{vs}$. $\mathrm{HG}+\mathrm{sI} / \mathrm{R}$ as determined by ANOVA. (C) The H9c2 cells were induced with high-glucose condition and treatment with SB203580 supplemented with 2'7-dichlorofluorescein diacetate dye for $24 \mathrm{~h}$. Intracellular ROS production was measured. Each bar graph represents the mean \pm SEM. ${ }^{*} \mathrm{P}<0.05$ vs. NG; ${ }^{*} \mathrm{P}<0.05$ vs. $\mathrm{HG}$ as determined by ANOVA. ROS, reactive oxygen species; NG, normal glucose; HG, high glucose; sI/R, simulated ischemia/reperfusion. 


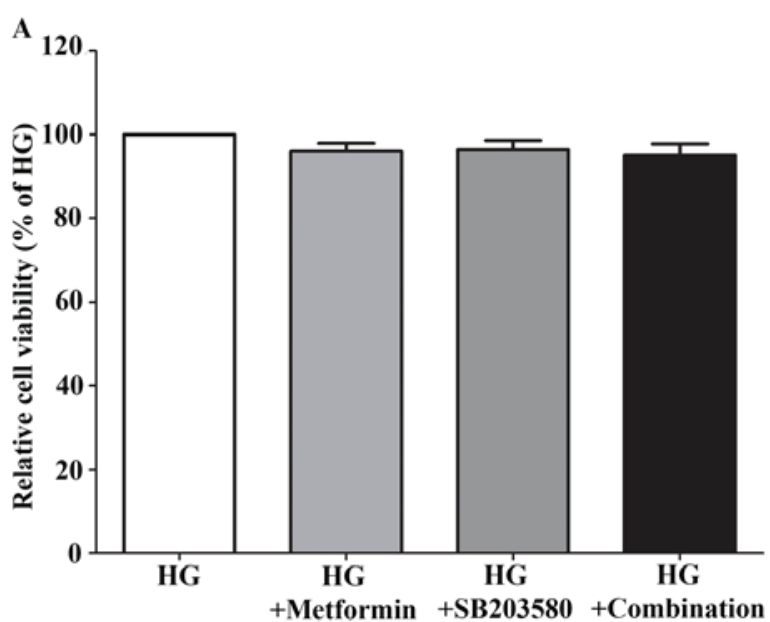

B

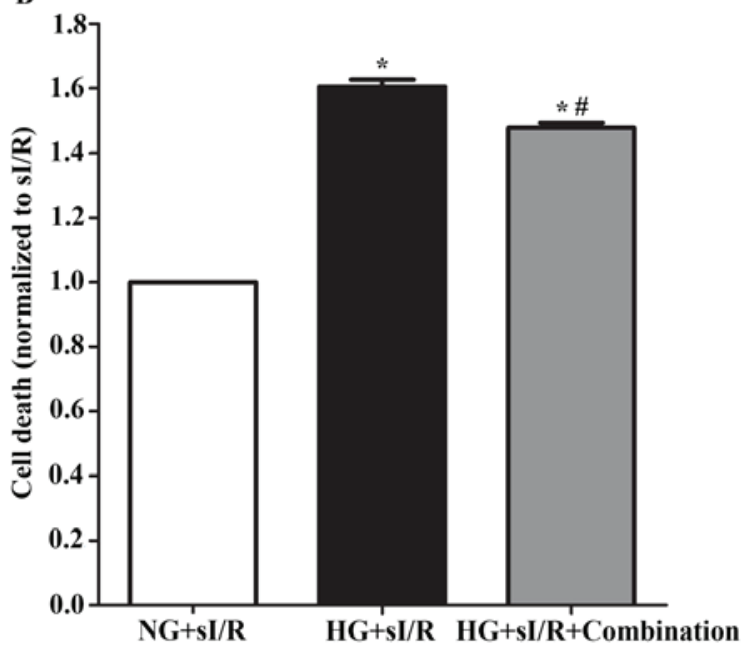

C

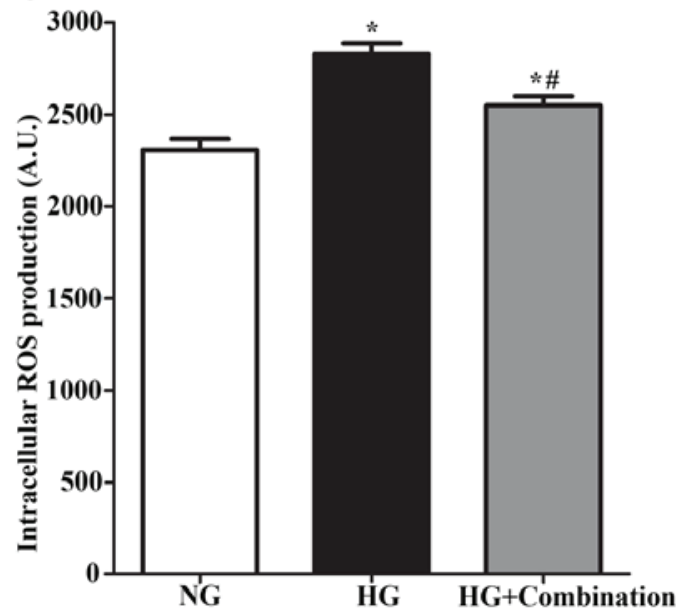

Figure 4. Determination of the effect of combination of treatment with metformin and SB203580 in H9c2 cells on high-glucose and sI/R condition. (A) H9c2 cells was induced high-glucose condition supplement with or without $3 \mathrm{mM}$ of metformin and $10 \mu \mathrm{M}$ of SB203580 for $24 \mathrm{~h}$, then the cell viability was determined by using MTT cell survival assay. (B) H9c2 cells in high-glucose condition that treatment with combined drugs for $24 \mathrm{~h}$ were simulated ischemia for $40 \mathrm{~min}$ followed by $24 \mathrm{~h}$ of reperfusion. ${ }^{*} \mathrm{P}<0.05$ vs. NG+sI/R; ${ }^{\#} \mathrm{P}<0.05$ vs. HG+sI/R as determined by ANOVA. (C) H9c2 cells were induced high-glucose condition that treatment combined drugs supplement with 2'7-dichlorofluorescein diacetate dye for $24 \mathrm{~h}$. Then, the intracellular ROS production was measured. Each bar graph represents the mean \pm SEM. ${ }^{*} \mathrm{P}<0.05$ vs. $\mathrm{NG}$ and ${ }^{\#} \mathrm{P}<0.05$ vs. high-glucose group as determined by ANOVA. ROS, reactive oxygen species; NG, normal glucose; HG, high glucose; sI/R, simulated ischemia/reperfusion.
Metformin and SB203580 improve cardiac functions in lean $T 2 D M$ rats. To determine the cardiac function in the type 2 diabetic condition, all rats were measured in terms of cardiac function parameters by using echocardiography after 4 weeks of treatment. The results demonstrated that in the diabetic group, the heart wall thickness was shown to significantly decrease when compared to the control in LVIDd (0.387 \pm 0.014 vs. $0.655 \pm 0.028 \mathrm{~cm}, \mathrm{P}<0.05)$, LVIDs $(0.248 \pm 0.015$ vs. $0.432 \pm 0.029 \mathrm{~cm}, \mathrm{P}<0.05)$ and stability in LVPWd, LVPWs. Moreover, the GK rats had a significantly faster heart rate (HR) $(354.4 \pm 8.21$ vs. $494.5 \pm 20.75 \mathrm{bpm}$, $\mathrm{P}<0.05)$, lower in $\operatorname{EDV}(0.694 \pm 0.077$ vs. $0.152 \pm 0.016 \mathrm{ml}$, $\mathrm{P}<0.05)$ and ESV $(0.221 \pm 0.029$ vs. $0.048 \pm 0.007 \mathrm{ml}, \mathrm{P}<0.05)$, which was caused by a decrease in stroke volume (SV) $(0.473 \pm 0.055$ vs. $0.105 \pm 0.009 \mathrm{ml}, \mathrm{P}<0.05)$ and cardiac output (CO) $(0.169 \pm 0.022$ vs. $0.050 \pm 0.004 \mathrm{l} / \mathrm{min}, \mathrm{P}<0.05$; Table I).

Treatment with SB203580 could significantly improve heart rate $(443.9 \pm 30.13$ vs. $494.5 \pm 20.75$ bpm, $\mathrm{P}<0.05), \mathrm{SV}$ $(0.129 \pm 0.016$ vs. $0.105 \pm 0.009 \mathrm{ml}, \mathrm{P}<0.05)$, and $\mathrm{EF}(85.71 \pm 2.72$ vs. $70.68 \pm 2.42 \%, \mathrm{P}<0.05)$ compared to the diabetic group.

Treatment with the combination of metformin and SB203580 was able to significantly improve some parameters when compared to the diabetic group, including IVSs $(0.353 \pm 0.015$ vs. $0.295 \pm 0.004 \mathrm{~cm}, \mathrm{P}<0.05)$, LVIDd $(0.528 \pm 0.020$ vs. $0.387 \pm 0.014 \mathrm{~cm}, \mathrm{P}<0.05), \mathrm{HR}(421.6 \pm 12.04$ vs. $494.5 \pm 20.75 \mathrm{bpm}, \mathrm{P}<0.05)$, EDV $(0.387 \pm 0.041$ vs. $0.152 \pm 0.016 \mathrm{ml}, \mathrm{P}<0.05), \operatorname{ESV}(0.084 \pm 0.019$ vs. $0.048 \pm 0.007 \mathrm{ml}, \mathrm{P}<0.05), \mathrm{SV}(0.304 \pm 0.024 \mathrm{vs} .0 .105 \pm 0.009 \mathrm{ml}$, $\mathrm{P}<0.05), \mathrm{CO}(0.130 \pm 0.011$ vs. $0.050 \pm 0.004 \mathrm{l} / \mathrm{min}, \mathrm{P}<0.05)$, and EF $(80.09 \pm 2.72$ vs. $70.68 \pm 2.42 \%, \mathrm{P}<0.05)$. In addition, the combination of metformin and SB203580 was only able to improve LVIDd, SV, and CO, when compared to metformin or SB203580 alone.

Combination of metformin and SB203580 reduces the sensitivity to myocardial ischemia/reperfusion injury in lean T2DM rats. The sensitivity to myocardial ischemia/reperfusion injury was performed by an ex vivo Langendorff perfusion. The result demonstrated that the infarct size (percentage) of the diabetic group was significantly higher than that of the control group $(59.73 \pm 1.65$ vs. $43.41 \pm 3.27 \%, \mathrm{P}<0.05)$. Treatment with metformin or SB203580 or a combination of metformin and SB203580 significantly reduced the infarct size (percentage) when compare to the diabetic group $(59.73 \pm 1.65$ vs. $38.59 \pm 2.42 \%, 33.63 \pm 2.12 \%, 26.15 \pm 1.23 \%$, respectively; $\mathrm{P}<0.05)$. In addition, treatment of metformin in combination with SB203580 was further able to reduce the infarct size when compared to metformin or the SB203580 treated group. (Fig. 7; $\mathrm{P}<0.05$ )

Combination of metformin and SB203580 activates Akt phosphorylation and decreases apoptosis signaling in myocardial ischemia/reperfusion injury lean T2DM rats. To determine the effect of the combination of metformin and SB203580 in signal transduction on organ level response to myocardial ischemia/reperfusion injury, Western blotting analysis was performed on homogenated hearts. The results showed that the p38 MAPK activation significantly increased in response to diabetes complicated with ischemia/reperfusion injury when compared to the control group $(1.20 \pm 0.053$ vs. $0.82 \pm 0.029$; 

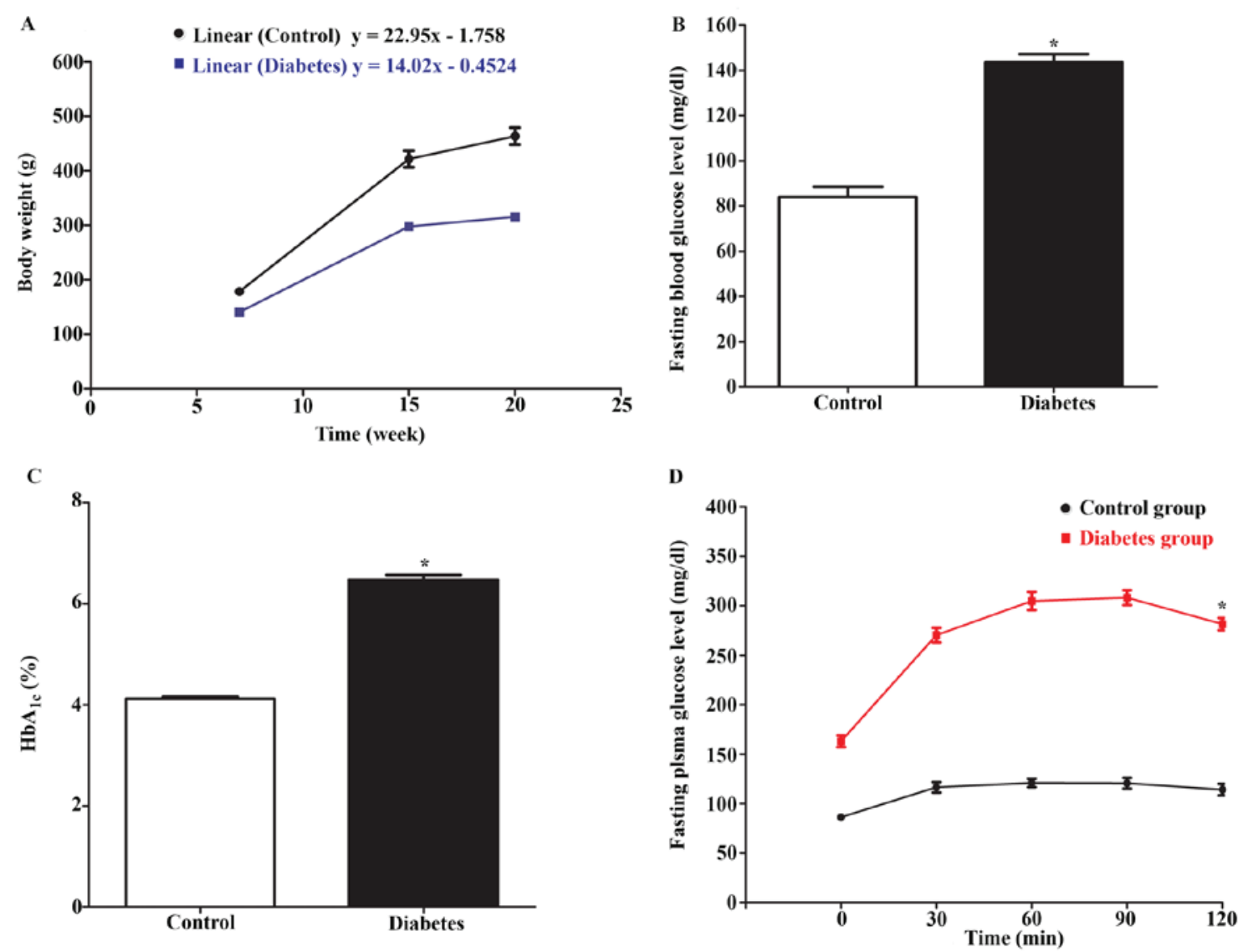

Figure 5. Determination of non-obese diabetic-like phenotype in animal model. The rats were assessed the non-obese diabetic-like phenotype by using the body weight and the blood samples from tail vein that collected after 12-14 h fasting. (A) Body weight of Wistar rats and GK rats. (B) Fasting blood glucose level of Wistar rats and GK rats before treatment. (C) $\mathrm{HbA}_{1 \mathrm{C}}$ level of Wistar rats and GK rats before treatment. (D) Oral glucose tolerance test of Wistar rats and GK rats before treatment. Each bar graph or line graph represents the mean \pm SEM. "P<0.05 vs. control group as determined by a t-test. GK, Goto-Kakizaki; $\mathrm{HbA}_{1 \mathrm{c}}$, hemoglobin $\mathrm{A}_{1 \mathrm{C}}$.

P $>0.05$, Fig. 8A). Treatment with metformin or SB203580 or a combination of metformin and SB203580 significantly reduced p38 MAPK activation $(1.20 \pm 0.053$ vs. $0.25 \pm 0.050$ or $0.34 \pm 0.076$ or $0.14 \pm 0.096 ; \mathrm{P}>0.05$, Fig. $8 \mathrm{~A}$ ). In this study, we also determined other survival (Akt) and apoptosis (Bax, Bcl-2 and caspase 3) signal transduction; the result demonstrated that the Akt phosphorylation was not different in the diabetes complicated with ischemia/reperfusion injury group when compared to the control group $(0.803 \pm 0.186$ and $0.792 \pm 0.076$, Fig. 8B). Treatment with metformin significantly increased Akt phosphorylation but was not significantly different in SB203580 treatment and combination treatment when compared to the diabetic complication with ischemia/reperfusion injury group $(0.792 \pm 0.076$ vs. $1.23 \pm 0.048,1.06 \pm 0.095,0.914 \pm 0.022$, Fig. 8B). Determination of apoptotic regulatory proteins showed that, in the diabetic group, the level of Bax/Bcl-2 ratio significantly increased $(0.59 \pm 0.18$ vs. $0.32 \pm 0.005 ; \mathrm{P}>0.05$, Fig. 8D) and caspase-3 level $(0.67 \pm 0.076$ vs. $0.21 \pm 0.006$, $\mathrm{P}<0.05$, Fig. $8 \mathrm{C}$ ) significantly increased when compared to the control group. Treatment with metformin or SB203580 significantly decreased levels of $\mathrm{Bax} / \mathrm{Bcl}-2$ ratio $(0.59 \pm 0.18$ vs. $0.098 \pm 0.02$ or $0.099 \pm 0.014, \mathrm{P}<0.05$; Fig. $8 \mathrm{D}$ ) but did not cause a significant different in caspase- 3 level $(0.51 \pm 0.03$ or $0.67 \pm 0.03$ vs. $0.67 \pm 0.076$; Fig. $8 \mathrm{C}$ ) when compared to the diabetic group. In addition, treatment with a combination of metformin and SB203580 significantly reduced the levels of Bax/Bcl-2 ratio $(0.59 \pm 0.18$ vs. $0.14 \pm 0.032, \mathrm{P}<0.05$; Fig. $8 \mathrm{D})$ and caspase- 3 level $(0.14 \pm 0.006$ vs. $0.67 \pm 0.006, \mathrm{P}<0.05$; Fig. 8C) when compared to the diabetic group.

\section{Discussion}

Diabetic cardiomyopathy is a complication of type 2 diabetic that is known as a major cause of morbidity and mortality in worldwide, especially myocardial ischemia/reperfusion injury. Metformin and SB203580 are also known to have cardio-protective effects on hyperglycaemic condition or hyperglycaemia with ischemia/reperfusion condition. In this study, we proposed that treatment with the combination of metformin and SB203580 could decrease cardiac cell death rates on hyperglycaemia subjected to ischemia/reperfusion condition. Therefore, the simulation of diabetes complicated with myocardial I/R injury condition causing cardiac cell death, as well as the effect of metformin, p38 MAPK inhibitor-SB203580, and a combination of these two drugs, were investigated in this study through carrying out in vitro and ex vivo experiments.

The major findings in this study showed that a high-glucose condition enhanced the sensitivity to ROS production and ischemia/reperfusion injury. Treatment with drugs could 

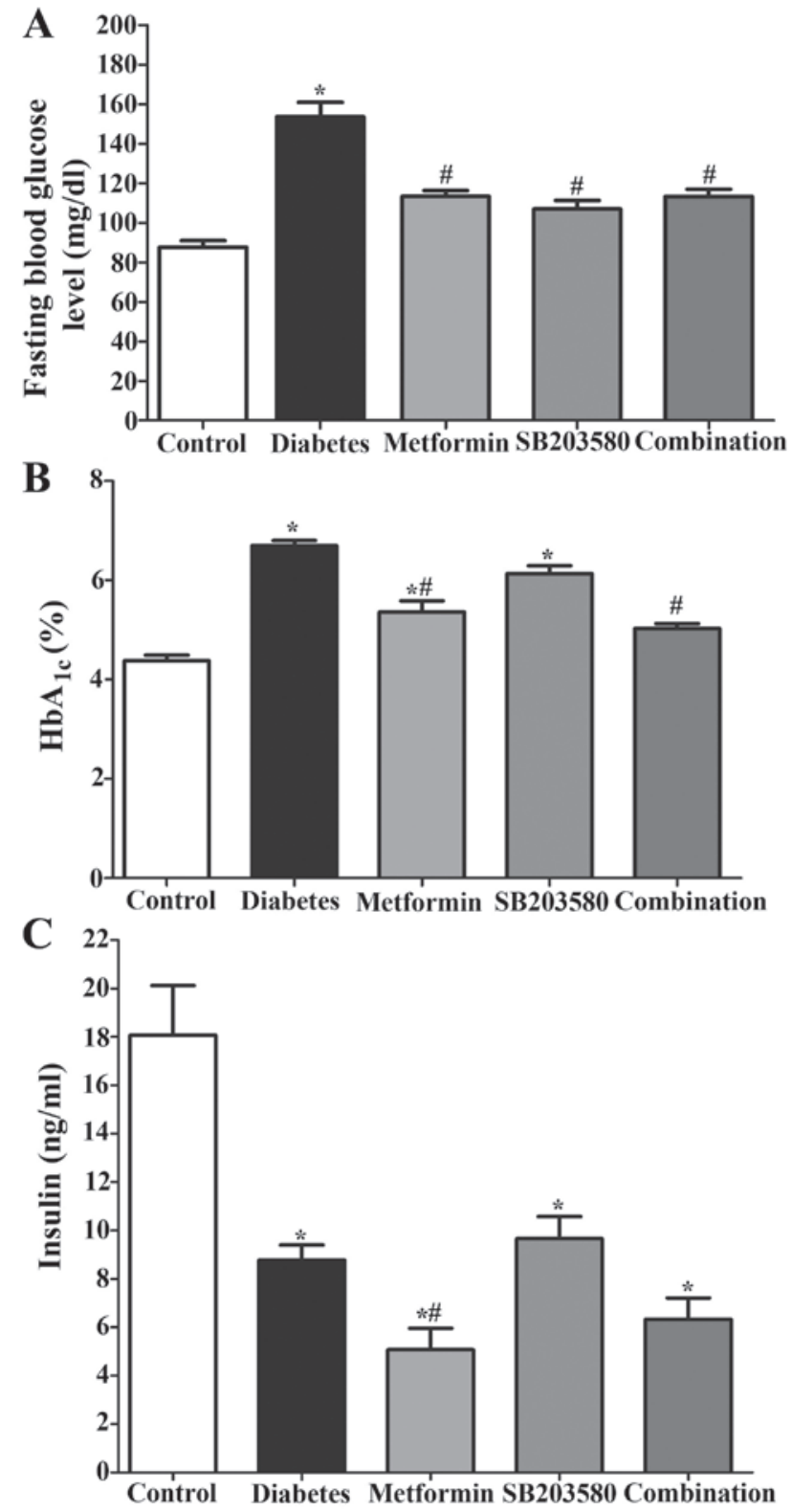

Figure 6. Determination of the effect of drugs on diabetic parameters in type 2 diabetic model. The rats were divided into 5 groups and treatment with or without metformin, SB203580, combination of drugs for 4 weeks. After that, the diabetic parameters were performed. (A) Fasting blood glucose level of Wistar rats and GK rats. (B) $\mathrm{HbA}_{1 \mathrm{C}}$ level of Wistar rats and $\mathrm{GK}$ rats. (C) Plasma insulin level of Wistar rats and GK rats. Each bar graph represents the mean \pm SEM. ${ }^{*} \mathrm{P}<0.05$ vs. control group; ${ }^{~} \mathrm{P}<0.05$ vs. diabetic group as determined by ANOVA. GK, Goto-Kakizaki; $\mathrm{HbA}_{1 \mathrm{c}}$, hemoglobin $\mathrm{A}_{1 \mathrm{C}}$.

reduce ROS generation and cardiac cell death. Treatment with metformin or SB203580 could significantly reduce the infarct size in ex vivo ischemia/reperfusion model of a lean-type 2 diabetic rat model. A combination of metformin and SB203580 could enhance cardioprotection.

From our in vitro findings, it was demonstrated that the hyperglycemic condition did not cause cardiac cell deaths but did seem to increase cell proliferation. This finding was in contradiction to findings of previous studies, which have reported that hyperglycemia is a cause of cell death $(19,20)$. This situation could be explained by the relationship between the Retinoid-IFN-Induced Mortality 19 (GRIM-19) expression levels and the activity of STAT3 signaling, which was reported by Li et al in 2016 (21). In that study, they induced a hyperglycemic condition in $\mathrm{H} 9 \mathrm{c} 2$ cells and HeLa cells by using a $25 \mathrm{mM}$ glucose solution and it was subsequently found that the high-glucose solution increased cell proliferation in H9c2 cells and HeLa cells by down-regulated GRIM-19 expression leading to impairments in mitochondrial Complex-I function and increased phosphorylated STAT3 levels, all of which play roles in cell proliferation or survival of cells (21). However, the mechanism of down-regulated Grim-19 expression that can activate STAT3 signaling in the high-glucose condition has been unknown. Thus, the mechanism of Grom-19 that induces STAT3 signal activation in a high-glucose condition should be investigated. However, in this study, the hyperglycemic condition did not increase cell death rate or non-cytotoxic in $\mathrm{H} 9 \mathrm{c} 2$ cell line but the hyperglycemic condition also increased the intracellular ROS production, which is a major cause of cell injury. Moreover, our findings also demonstrate that the hyperglycemic condition could aggravate cardiac cells on ischemia/reperfusion injury more than the normal condition. From this result, the increasing sensitivity of ischemia/reperfusion induced cellular injury and death in a hyperglycemic condition may be caused by a high-glucose inducing an increasing level of intracellular ROS generation, which is similar to the other previous findings in which the high-glucose condition stimulated ROS generation, which induced myocyte apoptosis in diabetic cardiomyopathy (22) and aggravated cardiac cell (H9c2 cell) injury and death when complicated with myocardial ischemia/reperfusion injury (18). This finding was consistent to the ex vivo experiment, which demonstrated that the stimulation of I/R injury in diabetes (GK rats) could increase infarct size. Our findings seem show that I/R injury condition could induce cardiac cell death (Infarct size) on diabetic heart more than in cardiac (H9c2) cells, which is an induced hyperglycemic condition. These findings may be due to the difference of physiology between cardiac (H9c2) cells and whole hearts because whole hearts are comprised of approximately $70 \%$ non-myocytes, especially the cardiac fibroblast, which has been reported that the stimulation of I/R injury could increase cardiac fibroblast cell death (23).

One of the major causes of aggravated cardiac cell death on diabetic cardiomyopathy is an increase in basal p38 MAP Kinase (p38 MAPK) activation in cardiac cells. Therefore, an inhibition of p38 MAPK activation could be a beneficial and therapeutic type of treatment for diabetic cardiomyopathy. In addition, metformin, which is an anti-diabetic drug, has also been demonstrated to have cardio-protective effects on ischemia/reperfusion injury (24). This is in relation to the cardio-protective effects of metformin itself and SB203580 itself on a hyperglycemic condition or hyperglycemia with ischemia/reperfusion condition. Thus, in this study, we proposed that treatment with the combination of metformin and SB203580 could reduce cardiac cell death on hyperglycemia with ischemia/reperfusion condition. Our results showed that treatment with metformin or SB203580 or the combination of metformin and SB203580 did not affect cell viability of cardiac cells ( $\mathrm{H} 9 \mathrm{c} 2$ cells) in a hyperglycemic condition. This result may have been observed due to the fact that the high-glucose condition was not toxic on cardiac cell viability. However, treatment with these drugs in the hyperglycemic condition was able to reduce intracellular ROS generation, 
Table I. Determination of cardiac function parameters after treatment in type 2 diabetic model.

\begin{tabular}{llllll}
\hline & \multicolumn{4}{c}{ Groups } & \\
\cline { 2 - 6 } Parameters & Control & Diabetes & Metformin & SB203580 & Combination \\
\hline IVSd (cm) & $0.273 \pm 0.010$ & $0.258 \pm 0.006$ & $0.222 \pm 0.011^{\mathrm{a}}$ & $0.249 \pm 0.014$ & $0.246 \pm 0.014$ \\
IVSs (cm) & $0.327 \pm 0.014$ & $0.295 \pm 0.004$ & $0.287 \pm 0.013$ & $0.329 \pm 0.020$ & $0.353 \pm 0.015^{\mathrm{b}}$ \\
LVIDd (cm) & $0.655 \pm 0.028$ & $0.387 \pm 0.014^{\mathrm{a}}$ & $0.440 \pm 0.029^{\mathrm{a}}$ & $0.371 \pm 0.015^{\mathrm{a}}$ & $0.528 \pm 0.020^{\mathrm{a}-\mathrm{c}}$ \\
LVIDs (cm) & $0.432 \pm 0.029$ & $0.248 \pm 0.015^{\mathrm{a}}$ & $0.284 \pm 0.030^{\mathrm{a}}$ & $0.183 \pm 0.011^{\mathrm{a}}$ & $0.286 \pm 0.023^{\mathrm{a}}$ \\
LVPWd (cm) & $0.285 \pm 0.016$ & $0.265 \pm 0.004$ & $0.256 \pm 0.017$ & $0.272 \pm 0.015$ & $0.262 \pm 0.016$ \\
LVPWs (cm) & $0.319 \pm 0.014$ & $0.329 \pm 0.033$ & $0.305 \pm 0.019$ & $0.304 \pm 0.016$ & $0.305 \pm 0.016$ \\
HR (Bpm) & $354.4 \pm 8.21$ & $494.5 \pm 20.75^{\mathrm{a}}$ & $463.0 \pm 11.43^{\mathrm{a}}$ & $443.9 \pm 30.13^{\mathrm{a}}$ & $421.6 \pm 12.04$ \\
EDV (ml) & $0.694 \pm 0.077$ & $0.152 \pm 0.016^{\mathrm{a}}$ & $0.246 \pm 0.040^{\mathrm{a}}$ & $0.142 \pm 0.015^{\mathrm{a}}$ & $0.387 \pm 0.041^{\mathrm{a}, \mathrm{b}}$ \\
ESV (ml) & $0.221 \pm 0.029$ & $0.048 \pm 0.007^{\mathrm{a}}$ & $0.087 \pm 0.023^{\mathrm{a}}$ & $0.020 \pm 0.004^{\mathrm{a}}$ & $0.084 \pm 0.019^{\mathrm{a}}$ \\
SV (ml) & $0.473 \pm 0.055$ & $0.105 \pm 0.009^{\mathrm{a}}$ & $0.161 \pm 0.027^{\mathrm{a}}$ & $0.129 \pm 0.016^{\mathrm{a}}$ & $0.304 \pm 0.024^{\mathrm{a}-\mathrm{c}}$ \\
CO (1/min) & $0.169 \pm 0.022$ & $0.050 \pm 0.004^{\mathrm{a}}$ & $0.069 \pm 0.015^{\mathrm{a}}$ & $0.055 \pm 0.007^{\mathrm{a}}$ & $0.130 \pm 0.011^{\mathrm{b}, \mathrm{c}}$ \\
EF $(\%)$ & $67.78 \pm 2.43$ & $70.68 \pm 2.42$ & $67.98 \pm 4.93$ & $85.71 \pm 2.72^{\mathrm{a}, \mathrm{b}}$ & $80.09 \pm 2.72$ \\
\hline
\end{tabular}

The parameters of cardiac function of all the rats were assessed by echocardiography after treatment. Each parameter represents the mean $\pm \mathrm{SEM}$. ${ }^{a} \mathrm{P}<0.05$ vs. control group; ${ }^{b} \mathrm{P}<0.05$ vs. diabetic group; ${ }^{\mathrm{C}} \mathrm{P}<0.05$ vs. SB203580 group by ANOVA. IVSd, interventricular septum thickness at end-diastole; IVSs, interventricular septum thickness at end-systole; LVIDd, left ventricular internal dimension at end-diastole; LVIDs, left ventricular internal dimension at end-systole; LVPWd, left ventricular posterior wall thickness at end-diastole; LVPWs, left ventricular posterior wall thickness at end-systole; HR, heart rate; EDV, end-diastolic volume; ESV, end-systolic volume; SV, stock volume; CO, cardiac output; EF, ejection fraction.

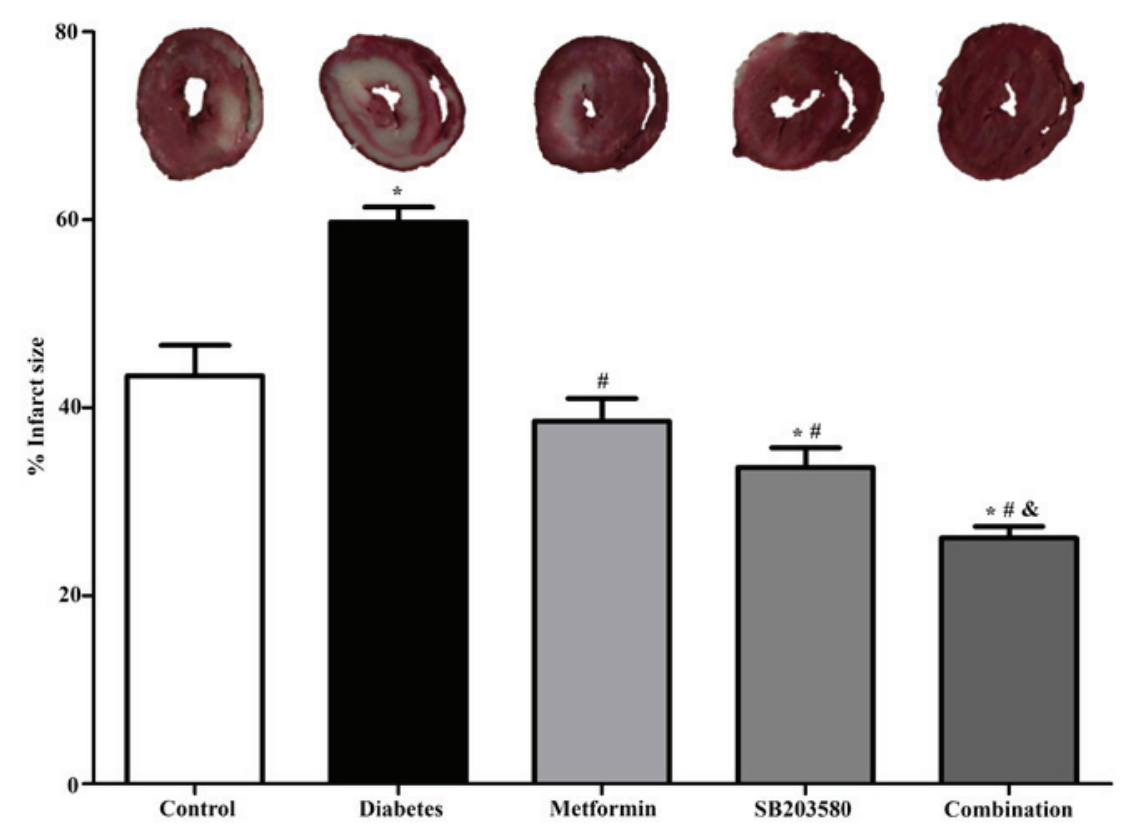

Figure 7. Determination of the effect of drugs on myocardial ischemia/reperfusion that caused complications in a type 2 diabetic model. After 4 weeks of treatment, all rats were subjected to myocardial ischemia/reperfusion injury using Langendorff Systems. The percentage infarct size was measured by triphenyltetrazolium chloride staining. Each bar graph represents the mean $\pm \mathrm{SEM}$. ${ }^{*} \mathrm{P}<0.05$ vs. control group; ${ }^{\#} \mathrm{P}<0.05$ vs. diabetes group; ${ }^{\&} \mathrm{P}<0.05$ vs. SB203580 as determined by ANOVA.

which may be a result of decreased rates of cardiac cell deaths on hyperglycemia subjected to the sI/R condition. This finding is similar to that of the ex vivo experiments, in which we found infarct size decreased after drug treatment. These findings, likewise with previous reports, showed that treatment with metformin or SB203580 on myocardial ischemia/reperfusion injury in diabetic model showed cardio-protective effects by improving cardiac function, reducing cell death rates, attenuating myocardial infarct size and improving ejection fraction (24-26). Previous studies have demonstrated that the 

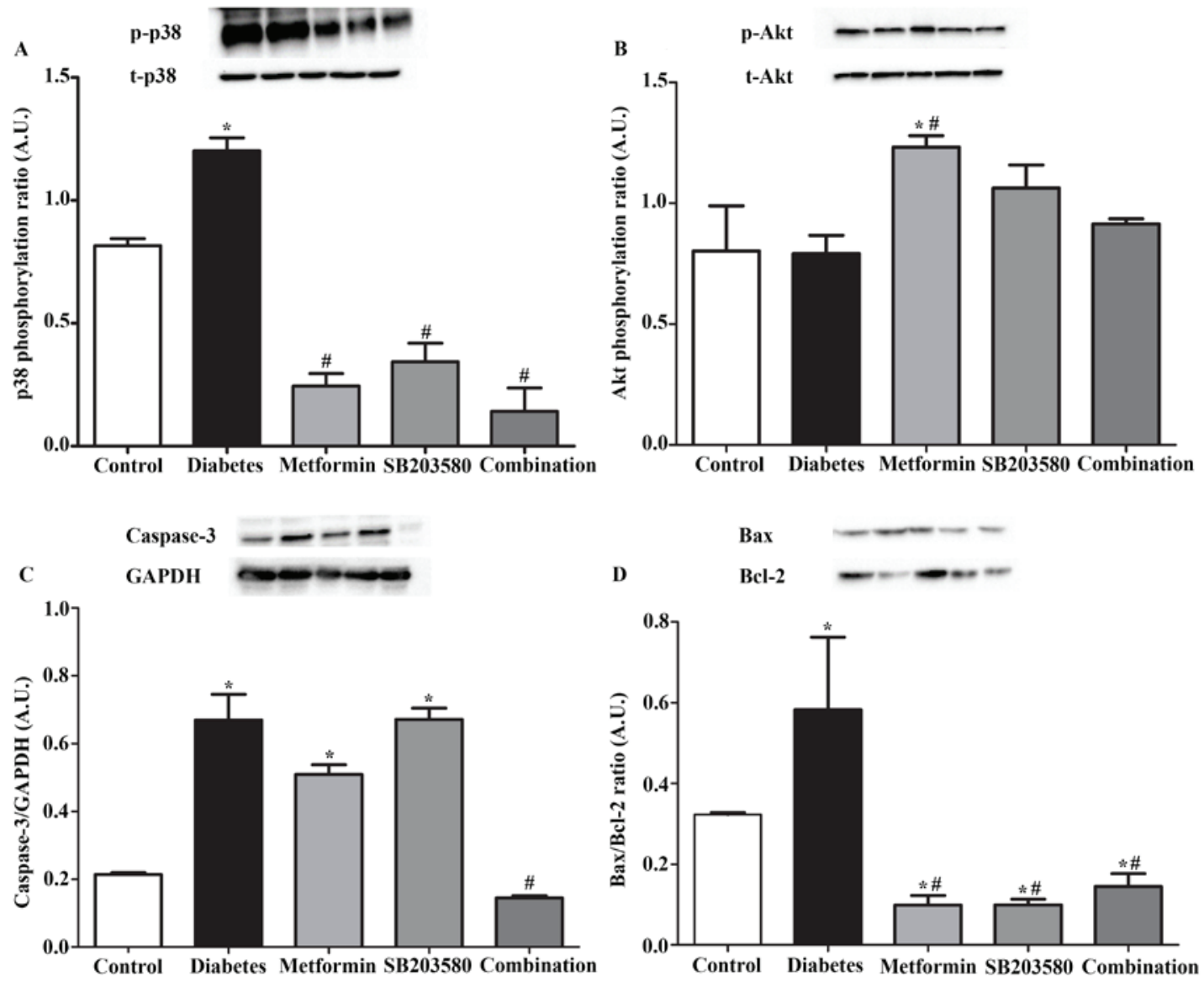

Figure 8. Determination of the effect of drugs on signaling transduction in the organ level response to myocardial ischemia/reperfusion that caused complications in a type 2 diabetic model. After 4 weeks of treatment, all rats were subjected to myocardial ischemia/reperfusion injury by using Langendorff Systems. Then, the expression protein was assessed by western blot analysis. (A) p38 MAPK activation through phosphorylation. (B) Akt activation through phosphorylation. (C) Expression of caspase-3. (D) Expression of Bax and Bcl-2. Each bar graph represents the mean \pm SEM. ${ }^{*} \mathrm{P}<0.05$ vs. control group; ${ }^{*} \mathrm{P}<0.05$ vs. diabetic group as determined by ANOVA. p, phosphorylated; $\mathrm{t}$, total.

GK rats sustained cardiomyocyte apoptosis by increasing p38 MAPK phosphorylation and increasing proapoptotic Bax protein (27), in the myocardial ischemia/reperfusion study. Moreover, previous studies have reported that metformin or SB203580 could reduce cardiac cell death rate in response to ischemia/reperfusion injury by increasing Akt phosphorylation and reducing $\mathrm{p} 38 \mathrm{MAPK}$ phosphorylation in rat MCs on high-glucose condition $(28,29)$. However, previous reports have focused on the effect of metformin or SB203580 in myocardial ischemia/reperfusion injury in diabetic models only; the effects of the combination of metformin and SB203580 on ischemia/reperfusion injury to diabetic heart have never previously been investigated. In this study, we found that the diabetic complicated with ischemia/reperfusion injury has an increase in p38 MAPK phosphorylation, Bax/Bcl-2 ratio and caspase- 3 level, which represents apoptosis. In addition, we also determined the effect of a combination of drugs on diabetes subjected to ischemia/reperfusion injury. Interestingly, we found that the combination of metformin and SB203580 showed the synergistic effects for reducing cardiac cell death on both of cardiac (H9c2) cells, which induced hyperglycemia with sI/R injury, and diabetic hearts with I/R injury by diminishing p38 MAPK phosphorylation, levels of Bax/Bcl-2 ratio and caspase-3 level; however, Akt phosphorylation did not increase. However, in this study, only the effects of a combination between drugs on diabetic parameters were determined. The interaction and toxicity of this combination of drugs in diabetic condition needs to be investigated further in order to obtain a clearer picture and precise therapeutic potential of using a combination of metformin and SB203580 in those with diabetes or diabetic complication disease, particularly cardiovascular disease.

The most common cause of diabetes is obesity; however, in actual fact, obese and non-obese people are at risk of type 2 diabetic disease. In particular, there have been several reports that type 2 diabetes was commonly occurs in non-obese people within Asia (30-32). From this, it can be suggested that even non-obese people are at risk of developing type 2 diabetic in Asian counties. So, the non-obese diabetic models are appropriate for use in diabetic-related studies. Therefore, the Goto-kakizaki rat (GK rat), which is used as a spontaneous type 2 diabetes non-obese model, was used in this study for simulating diabetic conditions. In our study, the GK rats were diagnosed type 2 diabetic disease by using the human diabetic criteria based on the American Diabetes Association (ADA) guideline 2017 (33); this was due to a lack of diagnostic criteria for diabetes in animals and in order to actually simulate a human diabetic condition. Our findings demonstrated that the GK rats exhibited diabetic characteristics following in line with human diabetic criteria, including a fasted-state blood glucose 
level of more than $126 \mathrm{mg} / \mathrm{dl}$, the $\mathrm{HbA}_{\mathrm{lc}}$ level almost $6.5 \%$ and OGTT level more than $200 \mathrm{mg} / \mathrm{dl}$. In addition, the confirmation of non-obese model was performed by using body weight; from the results, it was found that the average body weight of GK rats was lower than Wistar rats. These findings suggest that the GK rat has a non-obese type 2 diabetic-like phenotype. However, the body weight measurement alone may be not enough for accurate non-obese model confirmation. In fact, previous evidence has assessed non-obese models by using many parameters, including body weight, food intake, and length of bones, length of the body and the length of the tail. Therefore, other parameters need to applied for further investigation (34-36).

After diabetic diagnosis, the effect of metformin (anti-diabetic drug) or SB203580 (p38 MAPK inhibitor) or a combination of drugs was investigated on diabetic parameters, the plasma insulin level and cardiac function parameters. In this study, we found that treatment with all drugs could significantly decrease diabetic criteria (fasting blood glucose level and $\mathrm{HbA}_{1 \mathrm{c}}$ level). Moreover, treatment with metformin or a combination of drugs could reduce plasma insulin levels. Our findings regarding metformin treatment were similar to those of the reports from previous studies, in which it was found that metformin could increase glucose uptake leading to a decrease in plasma glucose level, decrease in hepatic gluconeogenesis and increase in insulin stimulated peripheral glucose uptake (although there is no change or increase in the insulin secretory responses) (37,38). In addition, our findings indicated that metformin could improve insulin sensitivity by reducing the plasma insulin levels in GK rats, but this was the only determination of metformin on plasma insulin levels. The assessment of insulin sensitivity needs to be investigated in order to confirm the potential for improving the insulin sensitivity of metformin.

Previous studies have indicated treatment with SB203580 in diabetic cells could increase glucose uptake $(39,40)$ but this does not have a significant effect on the stimulation of insulin secretion (41). This evidence provides a clearer picture on the effect of SB203580 treatment on high-glucose or hyperglycemic condition in cellular responses (in vitro). It would appear that this study is the first of its kind to determine the effective glycemic parameters (fasting blood glucose levels, $\mathrm{HbA}_{1 \mathrm{c}}$ levels, plasma insulin levels) of SB203580 treatment in a diabetic animal model. Interestingly, our findings found that treatment of SB203580 also reduces blood glucose levels, reduces the percentage of $\mathrm{HbA}_{1 \mathrm{c}}$ levels and did not have an effect on plasma insulin levels.

In this study, the effects of using a combination of metformin and SB203580 on diabetic parameters were assessed. Our findings demonstrated that treatment with combined drugs administered to GK rats (Diabetic condition) could reduce blood glucose levels, reduce $\mathrm{HbA}_{1 \mathrm{c}}$ levels and decrease plasma insulin levels. These results did not provide any further reduction to improve diabetic parameters of metformin and SB203580 combination, and remarkably, metformin or SB203580 did not interfere with each other in relation to improving diabetic parameters.

In this study, we also investigated the cardiac function after treatment and found that the GK rats displayed cardiac hypertrophy at 20-week-old, which was marked by stable left ventricular posterior wall thickness at end-diastole (LVPWd), reduction of cardiac output and a faster heart rate. Our findings were in conflict to previous studies, which have reported that the progression of hyperglycemic condition in GK rats leading to the left ventricle remodeling with marked hypertrophy, increase extracellular matrix deposition, and mild hypertension (9). Moreover, the 12 -week-old GK rats were increased in terms of heart weight-to-body weight ratio, left ventricle diameter at diastole, left ventricular posterior wall thickness at diastole, reduced cardiac output and heart rate, all of which resulted in cardiac hypertrophy and systolic dysfunction (42). In this situation, the differences in the results may be due to the age of the rats which is related to the change in cardiac function parameters. In addition, we found that treatment with a combination of drugs could improve cardiac function by increasing of SV and $\mathrm{CO}$. Our findings are consistent with previously reports, which found that treatment with metformin or SB203580 on myocardial ischemia/reperfusion injury in diabetic models showed cardio-protective effects, specifically, improving cardiac function, reduced cell death, attenuated myocardial infarct size and improved ejection fraction $(24,25)$.

In conclusion, metformin or SB203580 or a combination of metformin and SB203580 exhibited anti-diabetic effects by reducing diabetic parameters and improving insulin sensitivity. In addition, all of the drugs showed that there were improved cardio-protective effects on diabetic condition and diabetes complicated with myocardial ischemia/reperfusion injury condition in which the was a reduction of ROS generation (in vitro), decrease in cardiac cell death rate (in vitro), improvement in cardiac hypertrophy (in vivo) and decrease in cardiac infarct size (ex vivo), respectively. Therefore, we consider metformin or SB203580, especially used as a combination of drugs, to be a promising therapeutic agent that can be used against diabetes complicated with ischemia/reperfusion injury.

\section{Acknowledgements}

The authors would like to thank Professor Joel Nargeot, Institute of Functional Genomics (IGF), CNRS, INSERM, University of Montpellier for his suggestions and experiment planning.

\section{Funding}

The present study was financially supported by Naresuan University Research endowment fund and National Research Council of Thailand (NRC; grant no. R2560C138), and the Higher Education Research Promotion (HERP)-Office of Higher Education, Ministry of Education (grant no. R2559A017). The present study was also supported by The Royal Golden Jubilee Ph.D. Program-Thailand Research Fund (TRF) for JS (grant no. PHD/0087/2556) and for KK (grant no. PHD/0125/2558), The Naresuan University $\mathrm{PhD}$ student scholarship for NN, and Faculty of Allied Health Sciences, Naresuan University for providing research grant for Master degree study and scholarship for PM.

\section{Availability of data and materials}

The datasets used and/or analyzed during the current study are available from the corresponding author on reasonable request. 


\section{Authors' contributions}

JS and SK conceived and designed the experiments. JS, EP, PA, NN, PM and KK performed the animal experiments, determined the glycaemic parameters and assisted in the Langendorff protocol. JS and SK analyzed the data, and wrote and prepared the manuscript. AK and SP performed blind echocardiography and data analysis. SLB contributed to the infarct size measurement. JS, SLB and SK analyzed the data, and wrote, prepared, reviewed and corrected the manuscript.

\section{Ethics approval and consent to participate}

The animal experiments in this study were conducted according to the Guidance on the Operation of the Animals (Scientific Procedures) Act 1986 and the World Health Organization (WHO) Guidelines for Breeding and Care of Laboratory Animals. All the protocols were approved by the committee of the Centre for Animal Research, Naresuan University (approval no. NU AE581023). All procedures were designed to minimise the pain, suffering and distress of the animals involved.

\section{Patient consent for publication}

Not applicable.

\section{Competing interests}

The authors declare that they have no competing interests.

\section{References}

1. Cho NH, Shaw JE, Karuranga S, Huang Y, da Rocha Fernandes JD, Ohlrogge AW and Malanda B: IDF Diabetes Atlas: Global estimates of diabetes prevalence for 2017 and projections for 2045. Diabetes Res Clin Pract 138: 271-281, 2018.

2. American Diabetes Association: 2. Classification and diagnosis of diabetes. Diabetes Care 39 (Suppl 1): S13-S22, 2016.

3. Mathers CD and Loncar D: Projections of global mortality and burden of disease from 2002 to 2030. PLoS Med 3: e442, 2006.

4. Michael J and Fowler M: Microvascular and macrovascular complications of diabetes. Clin Diabetes 26: 77-82, 2008.

5. Morrish NJ, Wang SL, Stevens LK, Fuller JH and Keen H: Mortality and causes of death in the WHO multinational study of vascular disease in diabetes. Diabetologia 44 (Suppl 2): S14-S21, 2001.

6. Huang D, Refaat M, Mohammedi K, Jayyousi A, Al Suwaidi J and Abi Khalil C: Macrovascular complications in patients with diabetes and prediabetes. Biomed Res Int 2017: 7839101, 2017.

7. Yang B, Yang J, Bai J, Pu P, Liu J, Wang F and Ruan B: Suv39h1 protects from myocardial ischemia-reperfusion injury in diabetic rats. Cell Physiol Biochem 33: 1176-1185, 2014.

8. Wang ZV and Hill JA: Diabetic cardiomyopathy: Catabolism driving metabolism. Circulation 131: 771-773, 2015.

9. D'Souza A, Howarth FC, Yanni J, Dobryznski H, Boyett MR, Adeghate E, Bidasee KR and Singh J: Left ventricle structural remodelling in the prediabetic Goto-Kakizaki rat. Exp Physiol 96: 875-888, 2011.

10. Lee JC, Laydon JT, McDonnell PC, Gallagher TF, Kumar S, Green D, McNulty D, Blumenthal MJ, Heys JR, Landvatter SW, et al: A protein kinase involved in the regulation of inflammatory cytokine biosynthesis. Nature 372: 739-746, 1994.

11. Han J, Lee JD, Bibbs L and Ulevitch RJ: A MAP kinase targeted by endotoxin and hyperosmolarity in mammalian cells. Science 265: 808-811, 1994.
12. Gao Y, Kang L, Li C, Wang X, Sun C, Li Q, Liu R and Wang J: Resveratrol ameliorates diabetes-induced cardiac dysfunction through AT1R-ERK/p38 MAPK signaling pathway. Cardiovase Toxicol 16: 130-137, 2016

13. Shi L, Yu X, Yang H and Wu X: Advanced glycation end products induce human corneal epithelial cells apoptosis through generation of reactive oxygen species and activation of JNK and p38 MAPK pathways. PLoS One 8: e66781, 2013.

14. Yang J, Guo X, Yang J, Ding JW, Li S, Yang R, Fan ZX and Yang CJ: RP105 protects against apoptosis in ischemia/reperfusion-induced myocardial damage in rats by suppressing TLR4-mediated signaling pathways. Cell Physiol Biochem 36: 2137-2148, 2015.

15. Kumphune $\mathrm{S}$, Chattipakorn $\mathrm{S}$ and Chattipakorn N: Role of $\mathrm{p} 38$ inhibition in cardiac ischemia/reperfusion injury. Eur J Clin Pharmacol 68: 513-524, 2012.

16. Sasaki H, Asanuma H, Fujita M, Takahama H, Wakeno M, Ito S, Ogai A, Asakura M,Kim J,Minamino T, et al: Metformin prevents progression of heart failure in dogs: Role of AMP-activated protein kinase. Circulation 119: 2568-2577, 2009.

17. Gundewar S, Calvert JW, Jha S, Toedt-Pingel I, Ji SY, Nunez D, Ramachandran A, Anaya-Cisneros M, Tian R and Lefer DJ: Activation of AMP-activated protein kinase by metformin improves left ventricular function and survival in heart failure. Circ Res 104: 403-411, 2009.

18. $\mathrm{Hu} \mathrm{M}$, Ye P, Liao H, Chen M and Yang F: Metformin protects H9C2 cardiomyocytes from High-glucose and hypoxia/reoxygenation injury via inhibition of reactive oxygen species generation and inflammatory responses: Role of AMPK and JNK. J Diabetes Res 2016: 2961954, 2016.

19. $\mathrm{Xu} \mathrm{W,} \mathrm{Wu} \mathrm{W,} \mathrm{Chen} \mathrm{J,} \mathrm{Guo} \mathrm{R,} \mathrm{Lin} \mathrm{J,} \mathrm{Liao} \mathrm{X} \mathrm{and} \mathrm{Feng} \mathrm{J:}$ Exogenous hydrogen sulfide protects $\mathrm{H} 9 \mathrm{c} 2$ cardiac cells against high glucose-induced injury by inhibiting the activities of the p38 MAPK and ERK1/2 pathways. Int J Mol Med 32: 917-925, 2013.

20. Li K, Cui YC, Zhang H, Liu XP, Zhang D, Wu AL, Li JJ and Tang Y: Glutamine reduces the apoptosis of $\mathrm{H} 9 \mathrm{C} 2$ cells treated with High-glucose and reperfusion through an Oxidation-related mechanism. PLoS One 10: e132402, 2015.

21. Li YG, Han BB, Li F, Yu JW, Dong ZF, Niu GM, Qing YW, Li JB, Wei M and Zhu W: High Glucose induces down-regulated GRIM-19 expression to activate STAT3 signaling and promote cell proliferation in cell culture. PLoS One 11: e0153659, 2016.

22. Liu ZW, Zhu HT, Chen KL, Dong X, Wei J, Qiu C and Xue JH: Protein kinase RNA-like endoplasmic reticulum kinase (PERK) signaling pathway plays a major role in reactive oxygen species (ROS)-mediated endoplasmic reticulum stress-induced apoptosis in diabetic cardiomyopathy. Cardiovasc Diabetol 12: 158, 2013.

23. Paiyabhroma N, Nernpermpisooth $N$ and Kumphune $S$ : The recombinant human secretory leukocyte protease inhibitor (SLPI) protects cardiac fibroblasts injury against an in vitro ischemia/reperfusion injury. J Appl Pharm Sci 8: 156-162, 2018.

24. Kumphune S, Chattipakorn S and Chattipakorn N: Roles of p38-MAPK in insulin resistant heart: Evidence from bench to future bedside application. Curr Pharm Des 19: 5742-5754, 2013.

25. Kravchuk E, Grineva E, Bairamov A, Galagudza M and Vlasov T: The effect of metformin on the myocardial tolerance to ischemia-reperfusion injury in the rat model of diabetes mellitus type II. Exp Diabetes Res 2011: 907496, 2011.

26. Chen P, Yuan Y, Zhang T, Xu B, Gao Q and Guan T: Pentosan polysulfate ameliorates apoptosis and inflammation by suppressing activation of the p38 MAPK pathway in high glucosetreated HK2 cells. Int J Mol Med 41: 908-914, 2018.

27. Vahtola E, Louhelainen M, Forstén H, Merasto S, Raivio J, Kaheinen P, Kytö V, Tikkanen , Levijoki J and Mervaala E: Sirtuin1-p53, forkhead box O3a, p38 and post-infarct cardiac remodeling in the spontaneously diabetic Goto-Kakizaki rat. Cardiovase Diabetol 9: 5, 2010.

28. Kumphune S, Surinkaew S, Chattipakorn SC and Chattipakorn N: Inhibition of p38 MAPK activation protects cardiac mitochondria from ischemia/reperfusion injury. Pharm Biol 53: 1831-1841, 2015.

29. Driver C, Bamitale KDS, Kazi A, Olla M, Nyane NA and Owira PMO: Cardioprotective effects of metformin. J Cardiovasc Pharmacol 72: 121-127, 2018.

30. Seshadri KG: Non obesity, autoimmunity and the missing pieces of diabetes in the adult. Int J Diabetes Dev Ctries 33: 69-70, 2013.

31. Vaag A and Lund SS: Non-obese patients with type 2 diabetes and prediabetic subjects: Distinct phenotypes requiring special diabetes treatment and (or) prevention? Appl Physiol Nutr Metab 32: 912-920, 2007. 
32. Kashima S, Inoue K, Matsumoto M and Akimoto K: Prevalence and characteristics of non-obese diabetes in Japanese men and women: The Yuport medical checkup center study. J Diabetes 7: 523-530, 2015.

33. American Diabetes Associatio: Standards of medical care in diabetes-2017 abridged for primary care providers. Clin Diabetes 35: 5-26, 2017.

34. Ahmad T, Ohlsson C, Sääf M, Ostenson CG and Kreicbergs A: Skeletal changes in type-2 diabetic Goto-Kakizaki rats. J Endocrinol 178: 111-116, 2003.

35. Kuwabara WMT, Panveloski-Costa AC, Yokota CNF, Pereira JNB, Filho JM, Torres RP, Hirabara SM, Curi R and Alba-Loureiro TC: Comparison of Goto-Kakizaki rats and high fat diet-induced obese rats: Are they reliable models to study Type 2 diabetes mellitus? PLoS One 12: e0189622, 2017.

36. Hansson LI, Menander-Sellman K, Stenström A and Thorngren KG: Rate of normal longitudinal bone growth in the rat. Calcif Tissue Res 10: 238-251, 1972.

37. Yoshida T, Okuno A, Tanaka J, Takahashi K, Nakashima R, Kanda S, Ogawa J, Hagisawa Y and Fujiwara T: Metformin primarily decreases plasma glucose not by gluconeogenesis suppression but by activating glucose utilization in a non-obese type 2 diabetes Goto-Kakizaki rats. Eur J Pharmacol 623: 141-147, 2009.

38. Oh TJ, Shin JY, Kang GH, Park KS and Cho YM: Effect of the combination of metformin and fenofibrate on glucose homeostasis in diabetic Goto-Kakizaki rats. Exp Mol Med 45: e30, 2013.
39. Carlson CJ and Rondinone CM: Pharmacological inhibition of p38 MAP kinase results in improved glucose uptake in insulin-resistant 3T3-L1 adipocytes. Metabolism 54: 895-901, 2005.

40. Bazuine M, Carlotti F, Rabelink MJ, Vellinga J, Hoeben RC and Maassen JA: The p38 mitogen-activated protein kinase inhibitor SB203580 reduces glucose turnover by the glucose transporter-4 of 3T3-L1 adipocytes in the insulin-stimulated state. Endocrinology 146: 1818-1824, 2005.

41. Burns CJ, Howell SL, Jones PM and Persaud SJ: The p38 mitogen-activated protein kinase cascade is not required for the stimulation of insulin secretion from rat islets of Langerhans. Mol Cell Endocrinol 148: 29-35, 1999.

42. Vahtola E, Storvik M, Louhelainen M, Merasto S, Lakkisto P, Lakkisto J, Tikkanen I, Kaheinen P, Levijoki J and Mervaala E: Effects of levosimendan on cardiac gene expression profile and post-infarct cardiac remodelling in diabetic Goto-Kakizaki rats. Basic Clin Pharmacol Toxicol 109: 387-397, 2011.

c) (i) $\odot$ This work is licensed under a Creative Commons cc) Attribution-NonCommercial-NoDerivatives 4.0 International (CC BY-NC-ND 4.0) License. 